\title{
Convective Systems of the North Australian Monsoon
}

\author{
Mick PoPE \\ Bureau of Meteorology Training Centre, Bureau of Meteorology, Melbourne, Victoria, Australia \\ Christian Jakob and Michael J. Reeder \\ School of Mathematical Sciences, Monash University, Melbourne, Victoria, Australia
}

(Manuscript received 30 October 2007, in final form 27 February 2008)

\begin{abstract}
The climatology of convection over northern Australia and the surrounding oceans, based on six wet seasons (September-April), is derived from the Japanese Meteorological Agency Geostationary Meteorological Satellite-5 (GMS-5) IR1 channel for the years from 1995/96 to 2000/01. This is the first multiyear study of this kind. Clouds are identified at two cloud-top temperature thresholds: 235 and $208 \mathrm{~K}$. The annual cycle of cloudiness over northern Australia shows an initial (October-November) buildup over the Darwin region before widespread cloudiness develops over the entire region during the monsoon months (December-February), followed by a northward contraction during March and April. Tracking mesoscale convective systems (MCSs) reveals that both the size of the cloud systems and their lifetimes follow power-law distributions. For short-lived MCSs (less than $12 \mathrm{~h}$ ), the initial expansion of the cloudy area is related to the lifetime, with mergers important for long-lived MCSs (greater than $24 \mathrm{~h}$ ). During periods of deep zonal flow, which coincide with the active phase of the monsoon, the number of convective elements in the Darwin region peaks in the early afternoon, which is characteristic of the diurnal cycle over land. In contrast, when the zonal flow is deep and easterly and the monsoon is in a break phase, the areal extent of the convective elements in the Darwin region is greatest in the late morning, which is more typical of maritime convection.
\end{abstract}

\section{Introduction}

The climate of the earth is strongly affected by deep tropical convection, and northern Australia is an ideal environment in which to study it. The north Australian monsoon alternates between active periods of deep layer mean westerly zonal winds and break periods of deep easterly winds (Drosdowsky 1996). The MaddenJulian oscillation (MJO) plays a large role in modulating monsoon activity with strong active phases heralding the onset of the monsoon over Darwin (Wheeler and Hendon 2004). Large oceanic mesoscale convective systems (MCSs), which form during the active periods of the monsoon, commonly produce widespread rainfall (McBride and Frank 1999). During break periods, continental convection prevails, often triggered by seabreeze circulations (May et al. 2002). The character of

Corresponding author address: Mick Pope, Bureau of Meteorology Training Centre, Bureau of Meteorology, GPO Box 1289, Melbourne, VIC 3001, Australia.

E-mail: m.pope@bom.gov.au continental convection differs from that encountered during active monsoon periods. Isolated pulse convection and various propagating MCSs, such as squall lines (Chappel 2001), the north Australian cloud line (Drosdowsky and Holland 1987; Goler et al. 2006), and the famous "Hector" storms located over the Tiwi Islands (Carbone et al. 2000) north of Darwin, are typical examples of the continental convection over northern Australia. Given the wide variety of convective regimes observed in the northern Australian region and its surrounding ocean areas, it appears worthwhile to focus a study of convection on this area because its findings may have implications for the wider tropical western Pacific region and beyond.

Another important reason to focus on northern Australia is the existence of long-term detailed measurements of convection, precipitation, clouds, and radiation at Darwin, for instance, the long-term deployment of a polarimetric weather radar (Keenan et al. 1998) and the U.S. Department of Energy (DOE) Atmospheric Radiation Measurement (ARM) site (Ackerman and Stokes 2003; Mather et al. 1998). Furthermore, 
Darwin was recently the focus of the Tropical Warm Pool International Cloud Experiment (TWP-ICE; May et al. 2008). Given this focus on detailed long-term measurements at Darwin, it is important to place the Darwin region into a larger-scale context by determining how representative convection at Darwin is for the larger northern Australian region. If Darwin is representative of the broader region, under what conditions do the various types of convection occur? In particular, does the east-west zonal wind stratification of the environment represent a broadly representative continental-maritime convective system split, as suggested in earlier studies (Keenan and Carbone 1992)?

A widely used technique for developing climatological studies of convection is the identification and tracking of MCSs using infrared (IR) information from geostationary satellites (Williams and Houze 1987; Zuidema 2003; Machado and Laurent 2004; Kondo et al. 2006). In addition to diurnal and seasonal cycle, studies such as that of Machado and Laurent (2004) have used IR to study the relationship between the initial development of MCSs and their lifetime. The present study builds on these earlier studies and extends them in several important ways. First, it extends the application of IR techniques to the study of the North Australian monsoon. Kondo et al. (2006) presented an IR study over the tropical western Pacific and Maritime Continent; however, their study was limited to a single year. The present study extends this work, examining the seasonal cycle in addition to the diurnal cycle. The study also explicitly takes account of mergers between MCSs, which is commonly ignored in most similar studies (e.g., Machado and Laurent 2004). Infrared data are limited in that the cloud-top temperatures (CTTs) are relatively poorly related to precipitating areas because of nonraining anvil cloud (Liu et al. 2007), and they do not provide information about cloud microphysics and radiative transfer (Machado and Rossow 1993). Nonetheless, IR data from geostationary satellites have a higher time resolution than multichannel instruments aboard polar-orbiting satellites, and as such they can be used to track individual convective systems.

The objectives of this paper are to (i) construct a climatology of convection in the northern Australian region and its adjacent ocean areas, and (ii) to determine whether observations of convection taken at Darwin are likely to be representative of the region. The climatological part of this study includes an examination of the annual and diurnal cycles, as well as the life cycle of MCSs.

The dataset used and the cloud identification and tracking methods are described in section 2. Section 3 discusses the results of the cloud identification, while section 4 examines the statistics of convection tracked through time. The conclusions are presented in section 5 .

\section{Data and analysis methods}

\section{a. Dataset}

Cloud systems are identified and tracked using the IR1 channel (10.5-11.5 $\mu \mathrm{m})$ from the Japanese Meteorological Agency Geostationary Meteorological Satellite-5 (GMS-5). The geographical region is $5^{\circ}-25^{\circ} \mathrm{S}$, $120^{\circ}-150^{\circ} \mathrm{E}$ (Fig. 1), with a pixel resolution of $5 \times 5 \mathrm{~km}^{2}$ at the satellite subpoint. Calibration of GMS infrared radiances against other satellite measurements are discussed in Tokuno and Kurihara (1999) and Merchant et al. (2003). The period from 1995 to 2001 was chosen because hourly imagery is generally available; the main exception is a small gap in the 1998/99 season and the 1330 and 1430 UTC images, of which approximately $38 \%$ are missing. Each season consists of the months from September through to April. The period includes the north Australian monsoon (December-February), and two transition seasons. The early transition season (September-November) is known as the build up, during which lower-tropospheric moisture and convective activity increase. During the second transition season (March-April), the monsoon trough migrates northward and the southeasterly trade winds become reestablished.

\section{b. Cloud identification}

Clouds are identified from IR imagery using the algorithm of Williams and Houze (1987), which has been developed further by Mapes and Houze (1993). Pixels are identified as cloudy in each row of an image if their temperature is less than or equal to a predefined temperature threshold. A line cluster is defined as a row of contiguous pixels. Line clusters are matched with those in successive rows to form a cluster element (CE) when two successive line clusters share at least one column. The minimum size for CE identification is $75 \mathrm{~km}^{2}$, which is three or more pixels. Each hourly snapshot of CEs in the study area is treated as an independent sample. This will later be contrasted with statistics calculated by tracking CEs through their lifetimes.

Following Mapes and Houze (1993), CTT thresholds of 235 and $208 \mathrm{~K}$ are used. Typical justification for CTT threshold selections have been the relationship between temperature and precipitation. Arkin (1979) found a correlation between 6-h rainfall accumulation and cloud fractional coverage at $235 \mathrm{~K}$. Mapes and Houze (1993) identified areas of $208 \mathrm{~K}$, with regions of 


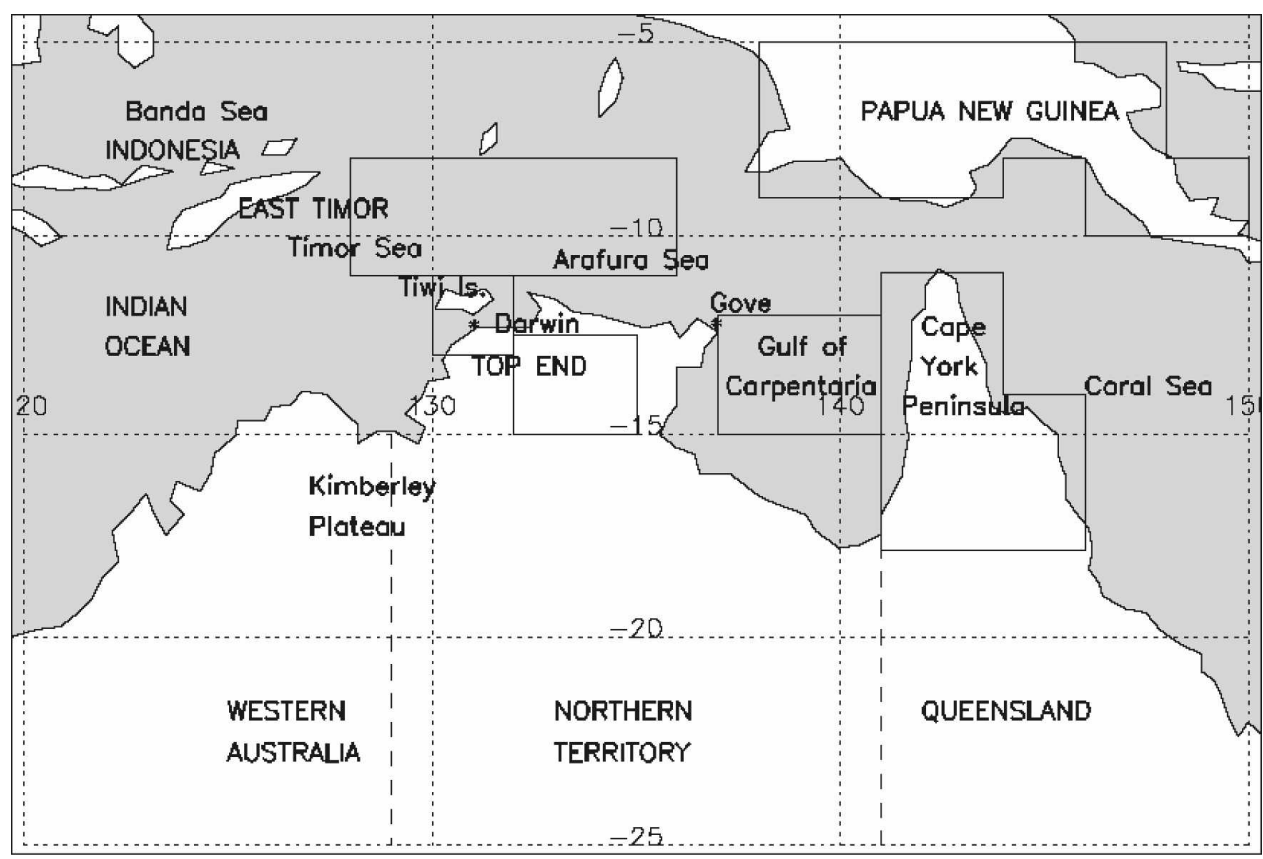

FIG. 1. Study area for the identification convective elements and mesoscale convective systems. The enclosed areas are discussed in the text.

instantaneous rainfall. Yuter and Houze (1998) found only a $55 \%$ probability of precipitation beneath pixels of IR temperature $<235 \mathrm{~K}$ and $88 \%$ probability of precipitation beneath IR temperature $<208 \mathrm{~K}$ for the Tropical Ocean and Global Atmosphere Coupled Ocean-Atmosphere Response Experiment (TOGA COARE) region. Both temperature thresholds are used here in order to distinguish clouds at different heights. Comparison to radiosonde data at Darwin implies that the $235-\mathrm{K}$ level lies on average below $11 \mathrm{~km}$ $(260 \mathrm{hPa})$ and $208 \mathrm{~K}$ around $14 \mathrm{~km}(155 \mathrm{hPa})$. Seasonal variations in these heights are small. Based on the 40-yr European Centre for Medium-Range Weather Forecasts (ECMWF) Re-Analysis (ERA-40), both CTTs are higher than the typical tropopause temperature, which is approximately $196 \mathrm{~K}$. The present study dataset contains approximately $4500000 \mathrm{CEs}$ when using the 235-K CTT threshold. For values much larger than $235 \mathrm{~K}$, the number of CEs will decrease as cloudy areas merge, or the possibility of counting surface pixels increases. Using the $208-\mathrm{K}$ threshold, the current dataset contains approximately $54000 \mathrm{CEs}$.

\section{c. Tracking clusters}

Convection observed using CE statistics represents a snapshot of the evolution in time of MCSs. In this study, MCSs are tracked by comparing CEs in successive frames, requiring a minimum CE size of $5000 \mathrm{~km}^{2}$.
CEs are identified as belonging to the same MCS if there is an overlap in area either between successive frames of $10000 \mathrm{~km}^{2}$ or $50 \%$ of either CE. The minimum size is set at $5000 \mathrm{~km}^{2}$ to ensure overlap occurs for rapidly propagating systems. The CEs are not allowed to be at the study area boundaries to ensure that they are tracked over their entire lifetime. Studies employing the minimum speed technique (e.g., Kondo et al. 2006) are able to use smaller minimum sizes. Genesis of an MCS is defined as the time of first appearance of the MCS at or above the minimum size threshold. MCS decay is defined as the last time the minimum size criterion is satisfied. MCSs are excluded from the dataset if any of the following conditions are met (the percentage excluded for the 235- and 208-K thresholds are given in parentheses):

1) The MCS lifetime is less than $2 \mathrm{~h}(77 \%, 88 \%)$.

2) MCS genesis occurs on the first image of a given season or decay occurs on the last image of the season. This ensures that an MCS is tracked for its entire lifetime $(<1 \%,<1 \%)$.

3) There is a gap of more than $3 \mathrm{~h}$ between successive images $(1 \%,<1 \%)$.

4) If the MCS first appears south of $20^{\circ} \mathrm{S}$. This condition removes midlatitude systems steered equatorward by deep westerly zonal winds $(23 \%, 11 \%)$.

5) The minimum CTT for one or more pixels within the MCS is less than $170 \mathrm{~K}$. Actual temperatures this 

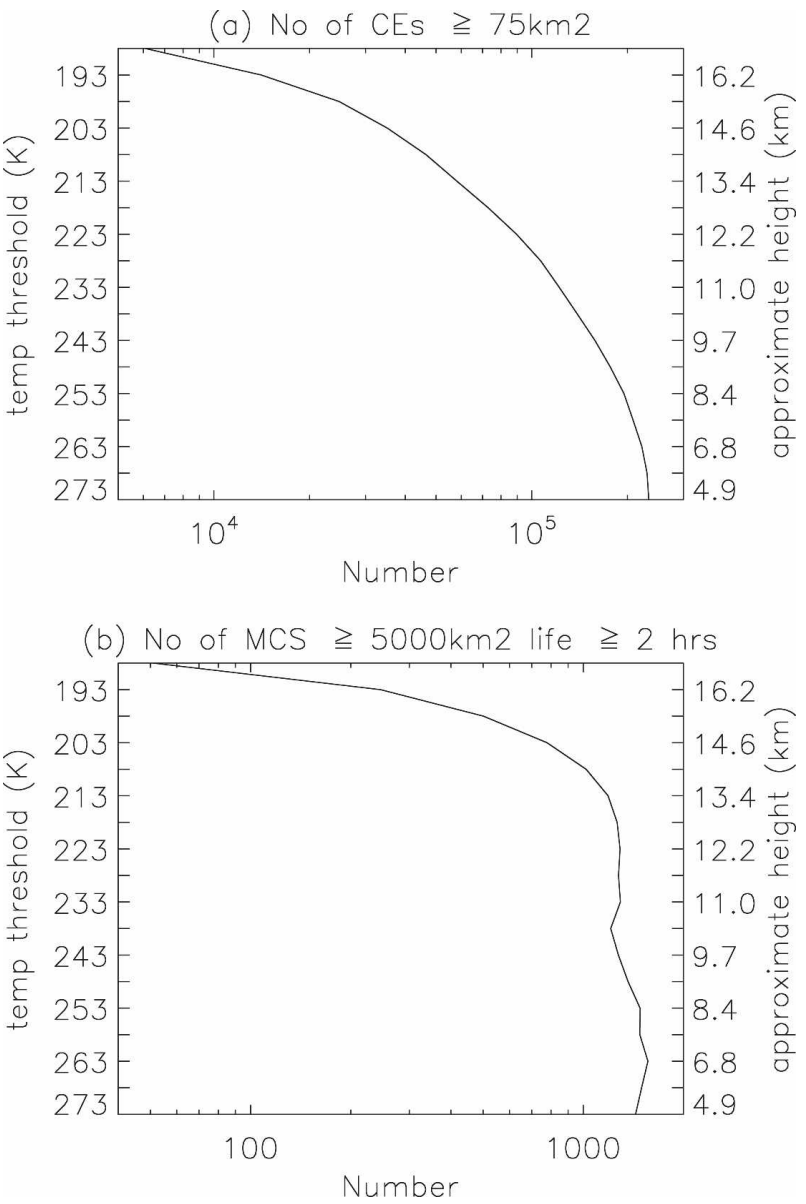

FIG. 2. Number of clouds identified using GMS imagery for temperature thresholds at $5-\mathrm{K}$ intervals. Corresponding heights are the seasonal (September-April) averages for the 2300 UTC Darwin sonde flight. (a) CEs identified where the minimum area is three GMS pixels (75 $\mathrm{km}^{2}$ at satellite subpoint). (b) MCS tracked for $2 \mathrm{~h}$ or more (CEs of area $\geq 5000 \mathrm{~km}^{2}$ are identified in three or more successive GMS images).

low are extremely rare, and those that were found in the dataset covered unrealistically large areas and were likely erroneous $(1 \%,<1 \%)$.

6) The calculated lifetime zonal propagation speed is greater than $60 \mathrm{~m} \mathrm{~s}^{-1}$. Unrealistic propagation speeds can result from mergers and decays of cloudy systems $(1 \%, 0 \%)$.

Following the evolution of MCSs through time and space allows for the examination of new properties of convective systems, such as their lifetime, areal expansion rates, and maxima and minima of various parameters over a systems lifetime.

Figure 2 shows the effect of the choice of temperature threshold on the number of CEs and MCSs identified. The number of CEs and MCSs detected increases with increasing temperature. The number of
MCSs is several orders of magnitude less than the number of CEs for all CTT thresholds. This is largely due to the much larger minimum size requirement. Mapes and Houze (1993) found that cloud clusters with areas $<1000 \mathrm{~km}^{2}$ accounted for approximately $80 \%$ of all clusters detected using a CTT threshold of $208 \mathrm{~K}$.

\section{Cluster element statistics}

In this section, the diurnal and annual cycles of convective activity associated with the north Australian monsoon, as well as the contribution to tropical cloudiness by convection of different sizes, are examined. As noted above, CEs are treated as independent, and hence individual convective systems may potentially contribute to the results many times over their lifetime. Nevertheless this view of convective systems provides a good first overview of their characteristics in the study area.

\section{a. Annual cycle}

Figure 3 shows maps of the frequency of occurrence of CEs per day for the 235-K threshold for selected months using the $\mathrm{CE}$ center on a $1^{\circ} \times 1^{\circ}$ grid. During October, most of the activity is in the northern part of the domain, while limited activity occurs over the western Top End (Fig. 1). Convection over the western Top End during this time of year has been associated with convergence on the sea-breeze front (May et al. 2002). During November and December, activity becomes more widespread and includes northern Australia. ERA-40 fields (not shown) show that this increase in activity is associated with increasing low-level specific humidity of the inland air lifted along the sea-breeze front. The southeast trade winds weaken and the developing heat low over the Kimberley Plateau (Fig. 1) advects moist air from a westerly direction over the Top End. [A climatology of the heat low and its associated dryline can be found in Arnup and Reeder (2007).] Increases in activity over Australia during December are often associated with monsoon onset (Drosdowsky 1996). The Australian monsoon season peaks in February, with the monsoon trough retreating north during March and April. During the entire period of September-April, the region of maximum activity is over Papua New Guinea (PNG), where coastal and orographic effects probably enhance the generation of convective clouds.

The numbers of CEs per day at the 208-K CTT threshold for October and February are show in Fig. 4. At the 208-K threshold, the number of CEs is an order of magnitude smaller than that at the $235-\mathrm{K}$ threshold, consistent with Fig. 2. This indicates that deep, intense 
(a) October $235 \mathrm{~K}$

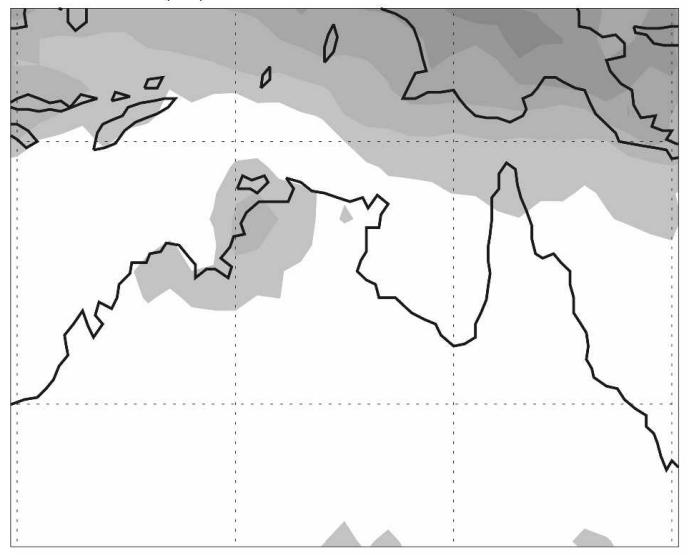

(c) February $235 \mathrm{~K}$

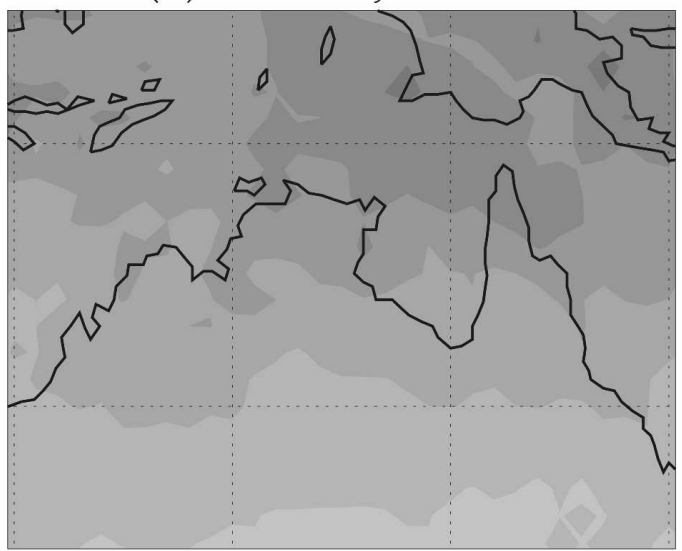

(b) December $235 \mathrm{~K}$

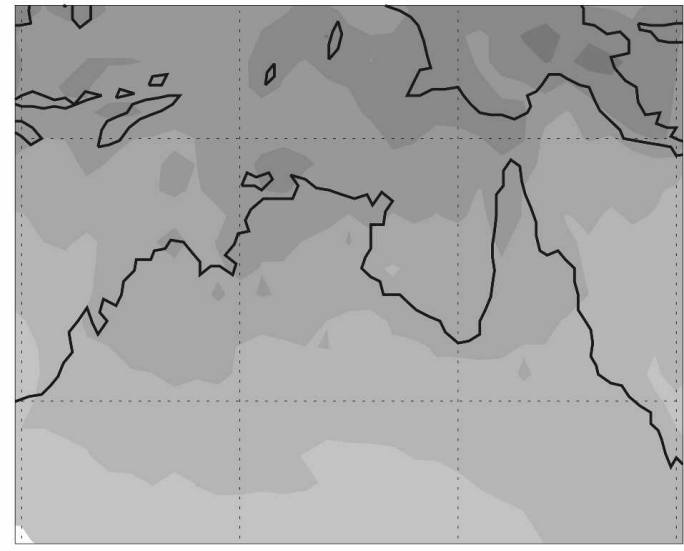

(d) April $235 \mathrm{~K}$

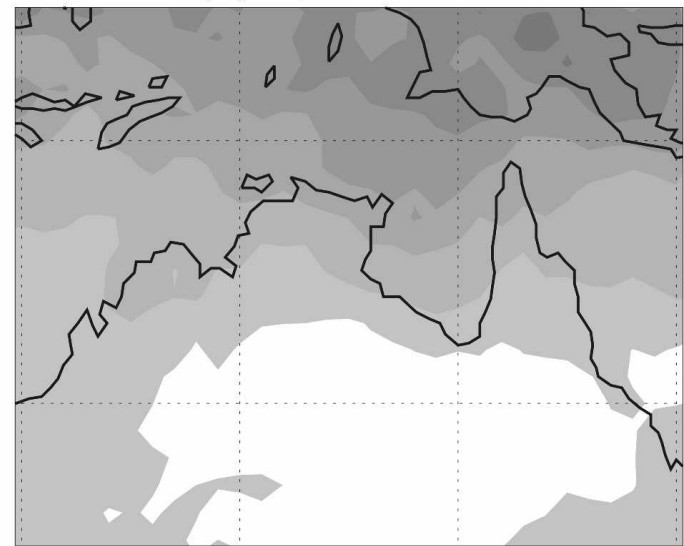

16

FIG. 3. CEs per day for a temperature threshold of $235 \mathrm{~K}$ and a minimum size of $75 \mathrm{~km}^{2}$ from (a) October, (b) December, (c) February, and (d) April for 1995/96-2000/01 seasons. Results are shown at a $1^{\circ} \times 1^{\circ}$ resolution.

convection occurs less frequently than shallower convection. The formation of CEs during October is limited largely to PNG, the Maritime Continent north of $10^{\circ} \mathrm{S}$, the Top End, and Cape York Peninsula. During February, activity over the Arafura Sea and Gulf of Carpentaria is prominent and associated principally with the presence of the monsoon trough, while a minimum in activity at the 208-K threshold is observed over PNG, which is not evident at the 235-K threshold. ERA-40 shows deep westerly winds over PNG during February (not shown) and an outward longwave radiation (OLR) minimum of $<200 \mathrm{~W} \mathrm{~m}^{-2}$, indicating cold cloud tops. The pattern of the average February rainfall for the period from 1995/95 to 2000/2001 from the Global Precipitation Climatology Project (GPCP; not shown) follows the geographical distribution of 208-K CEs more closely than that for $235-\mathrm{K}$ CEs. The reason for the differences in the CE distributions at the two temperature thresholds is discussed in section 4 .

Differences in convective activity are associated with differences in the thermodynamic and flow fields. To illustrate this, October and February temperature and wind profiles derived from 0930 central standard time (CST; +0930 UTC) Darwin radiosonde measurements are shown in Fig. 5. Before 1992, the minimum recorded dewpoint for radiosondes used at Darwin was $-50^{\circ} \mathrm{C}$, resulting in few measurements of dewpoint temperature for pressure smaller than $500 \mathrm{hPa}$; hence, the dewpoint profile is only shown to this level. The winds are displayed as their zonal and meridional components. During October, southeast trade winds blow across the Darwin region below $850 \mathrm{hPa}$. The shallow northerly wind may be due to flow into the heat low that forms over northwestern Australia at this time. A 
(a) October

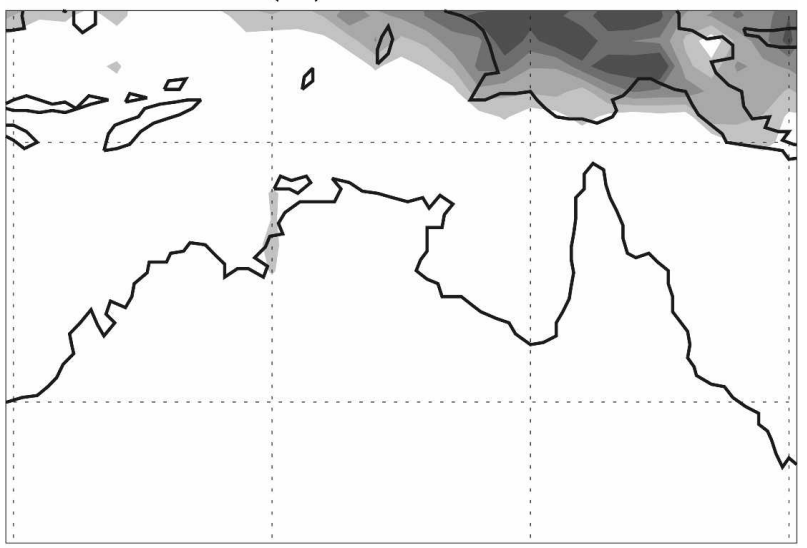

(b) February
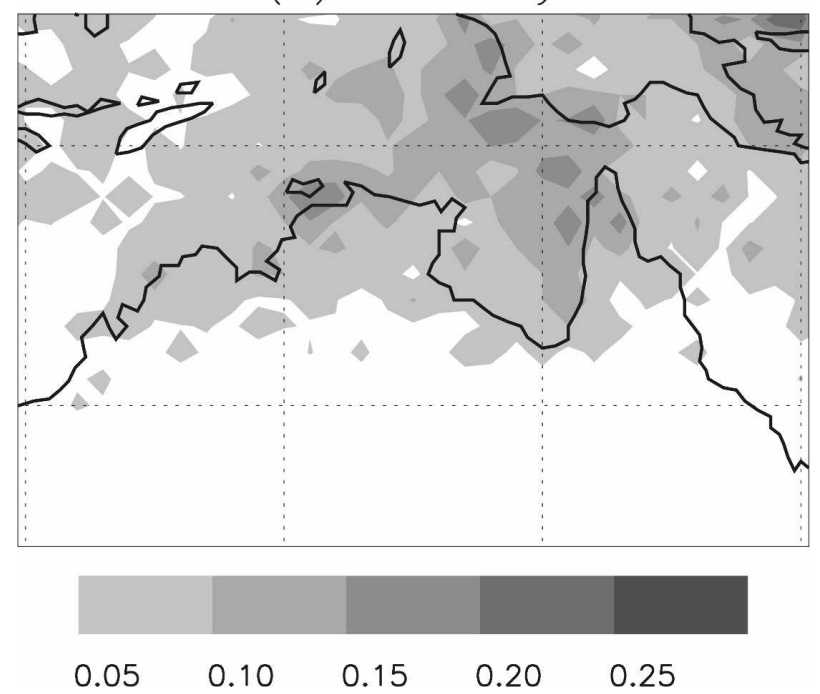

FIG. 4. CEs per day for a temperature threshold of $208 \mathrm{~K}$ and a minimum size of $75 \mathrm{~km}^{2}$ for the months of (a) October and (b) February for the 1995/96-2000/01 seasons. Results are shown at a $1^{\circ} \times 1^{\circ}$ resolution.

southeasterly jet exists near $700 \mathrm{hPa}$ (Chappel 2001), with dry mid- and lower-tropospheric air over northern Australia. As the trade winds weaken and the Kimberley heat low develops (from ERA-40; not shown), lower-tropospheric moisture increases, allowing convective activity to increase. By February, the monsoon is well established with deep convection over northern Australia (Figs. 3 and 4). A typical temperature profile has a temperature lapse rate close to a saturated adiabat and a small dewpoint depression through the depth of the troposphere (Fig. 5). Note that the February zonal wind profile is a composite of active and break monsoon days.

The average monthly convective available potential energy (CAPE), convective inhibition (CIN), and number of days on which the CAPE is zero at Darwin from the 0930 CST radiosonde for the months from September to April for 1959-2006 are shown in Fig. 6. The averages of CAPE and CIN are calculated using the maximum value of CAPE for parcels lifted from 850 $\mathrm{hPa}$ or below. Only nonzero values contribute to the mean. For days on which the CAPE is zero, CIN is undefined. September is the month of minimum mean CAPE, and the maximum number of days on which no CAPE exists. Mean monthly CIN varies weakly, reaching a maximum in November. Although not shown, over $50 \%$ of all days for the entire season have CIN values $<50 \mathrm{~J} \mathrm{~kg}^{-1}$. The interpretation of the mean monthly value of CIN is complicated by the number of days for which no CAPE exists. More convective inhibition occurs early and late in the seasons (between September and April) because of small values of lowlevel specific humidity as seen in ERA-40 (not shown). Likewise, the mean value of CAPE varies only weakly after the initial sharp increase between October and November, but the number of zero CAPE days continues to fall, reaching a minimum in February, associated with a peak in the Darwin monsoon. The Darwin sonde data may be taken as broadly representative of the wider area; however, results from TWP-ICE (May et al. 2008) show that for any given day, the wind and temperature profiles can vary considerably over $100 \mathrm{~km}$.

\section{b. Diurnal cycle}

Figure 7 illustrates the diurnal cycle of convection by showing maps of the occurrence of CEs per day at the 208-K threshold at 0900, 1500, 2100, and 0300 CST. This threshold was chosen to illustrate the diurnal cycle because the contrast between continental and oceanic activity is stronger than at $235 \mathrm{~K}$. At 1500 and $2100 \mathrm{CST}$, activity at this threshold is concentrated about the coastal regions of the Australian continent, PNG, and islands of the Indonesian Archipelago. At the 235-K threshold (not shown), activity is spread more broadly over the oceans, but is still concentrated over landmasses. The afternoon and early evening maxima in convective activity over northern Australia are consistent with previous studies (e.g., Keenan et al. 1989).

At 0300 and $0900 \mathrm{CST}$, CEs at the 208-K threshold are concentrated just off the coastlines around PNG. This nocturnal local coastal concentration of deep convection is consistent with studies for other locations (Yang and Slingo 2001; Zuidema 2003; Mapes et al. 2003). Suggested mechanisms include land-breeze convergence (Zuidema 2003) and gravity waves (Mapes et al. 2003). At $235 \mathrm{~K}$, there is evidence of a weak noc- 

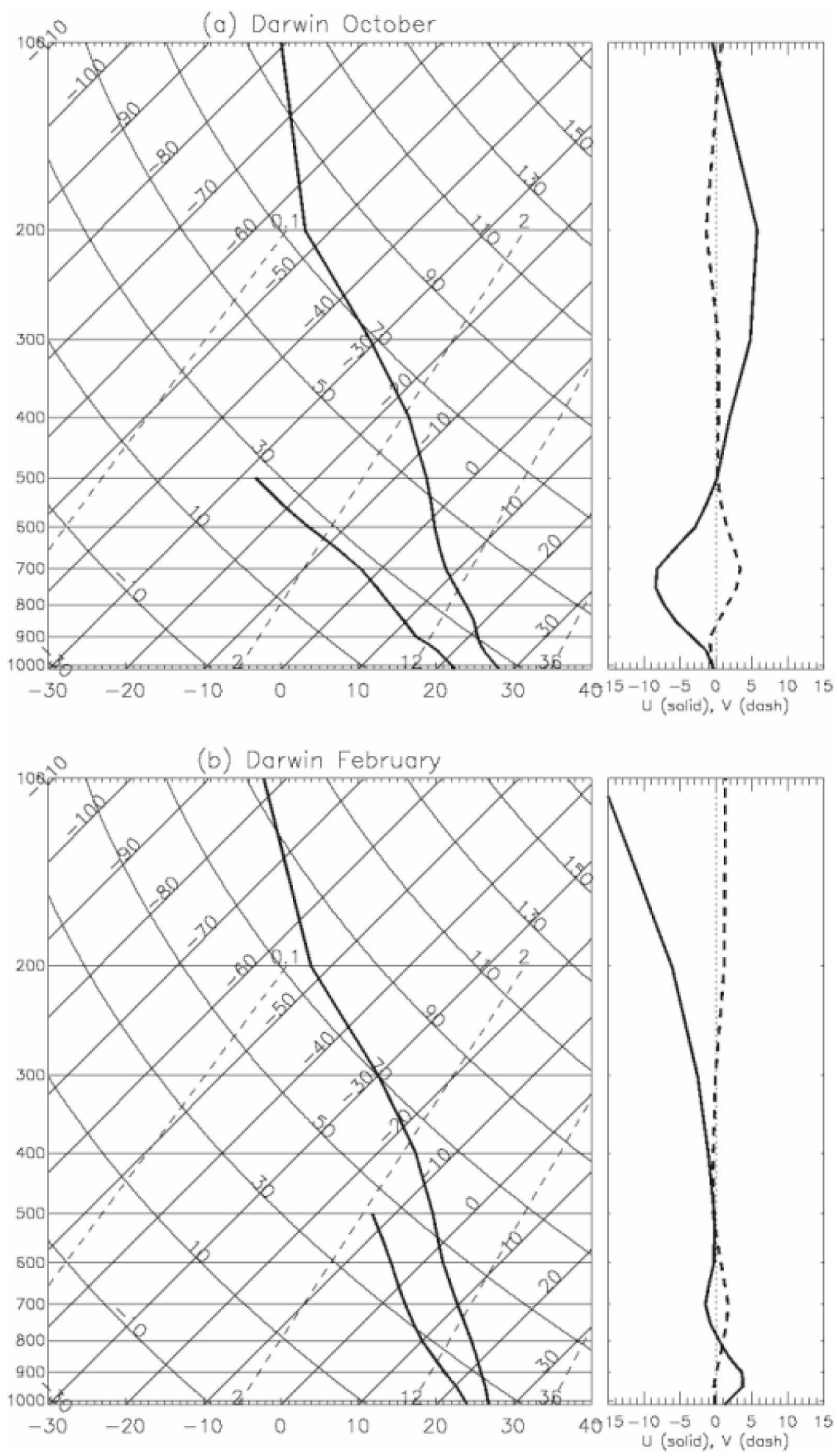

FIG. 5. Composite 2300 UTC sonde flights for Darwin for (a) October and (b) February for the 1959-2006 period. 


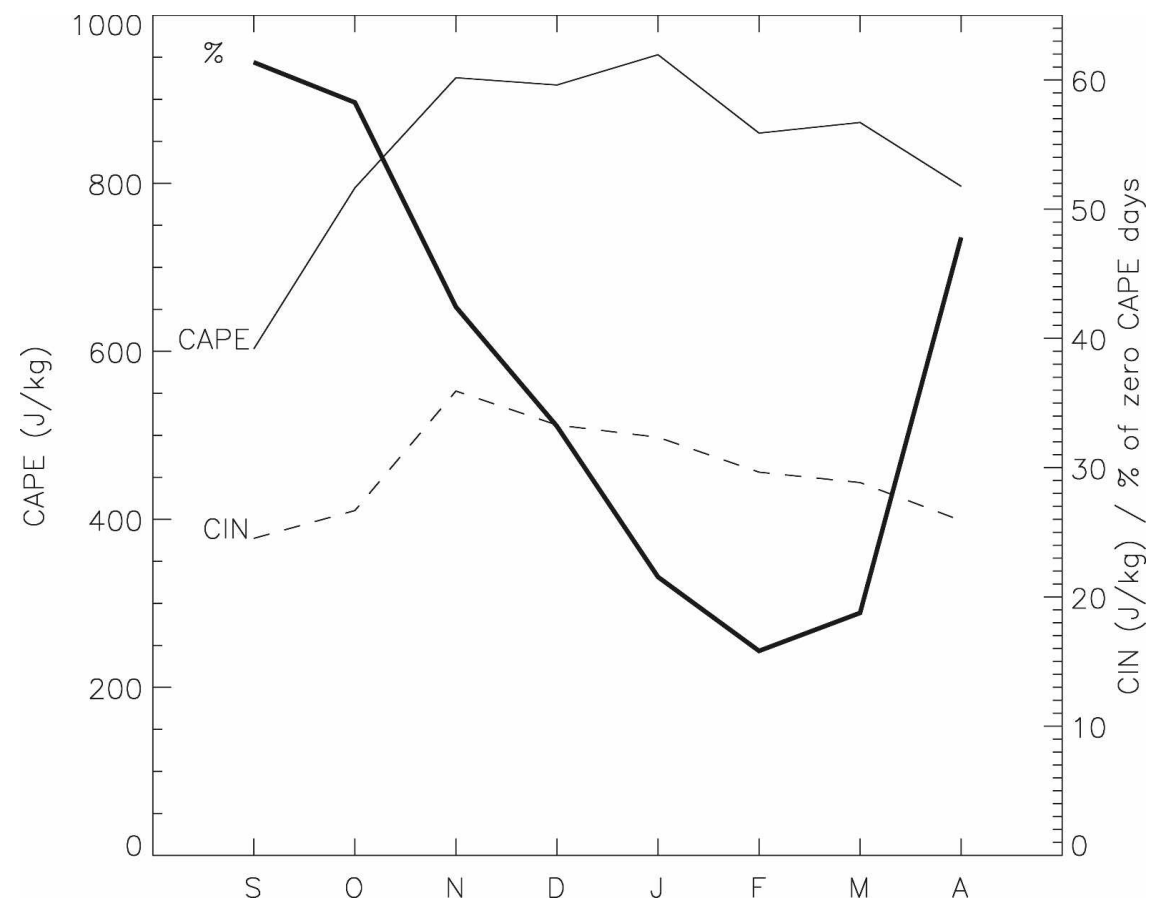

FIG. 6. Mean monthly CAPE, CIN, and percentage of days month ${ }^{-1}$ where CAPE is zero and hence CIN is undefined at Darwin for September-April for the 1959-2006 period for the 0930 LST radiosonde flight.

turnal increase in CE numbers in the Gulf of Carpentaria (not shown) that coincides with a decrease in $\mathrm{CE}$ number and cloudy area over Cape York Peninsula, and is consistent with the occurrence of cloud lines that develop over Cape York Peninsula during the day and propagate over the Gulf of Carpentaria during the night (Goler et al. 2006).

Figure 8 shows the diurnal cycle of $235-\mathrm{K}$ CEs for selected subregions defined in Fig. 1. The solid line shows the number of CEs per hour, normalized by the total daily number of CEs for that area. The dotted line shows the percentage of the area of the subregion that is covered in cloudiness at that temperature threshold. Results for 2400-0100 CST are omitted because of poor sampling resulting from the large number of missing images at these times. A high correlation between CE numbers and the percentage of the area covered by convection suggests that the large areal coverage is mainly due to the number of CEs. A low correlation indicates that areal coverage is mainly due to the size of each $\mathrm{CE}$ and is consistent with the development of fewer but more organized MCSs such as squall lines (Keenan and Carbone 1992). These later, larger CEs are more likely to consist of thick cirrus as convective activity peaks; however, use of IR data alone cannot determine this.

Coastal locations (Darwin and Cape York Peninsula) and PNG exhibit an afternoon maximum in CE numbers at the $235-\mathrm{K}$ threshold at $1500 \mathrm{CST}$, with the maximum cloudy area occurring approximately $3 \mathrm{~h}$ later. The subregion for Darwin used here includes the Tiwi Islands, where the MCS known as Hector forms. Observations have shown Hector increases in area as deep convective cells are triggered on the gust fronts of previous storms (Carbone et al. 2000). The inland Top End (labeled land in Fig. 8) CE number maximum occurs at $1600 \mathrm{CST}$, with the maximum cloudy area offset by $5 \mathrm{~h}$. These results suggest that the continental CE population is dominated by many small CEs early, with fewer larger CEs forming some 3-5 h later. This behavior has been observed for West Africa (Machado and Rossow 1993). Both the Timor Sea (labeled sea in Fig. 8) and the Gulf of Carpentaria show a weak peak in CE numbers and area near 1300 CST. The small phase lag between the number of CEs and their size indicates that the CEs are relatively small at this time. Chen and Houze (1997) noted that the large MCSs that dominate the oceans overnight form at about this time. During the early to midmorning 0400-1000 CST, CE numbers decrease over the oceans; however, the area coverage increases, which was also reported over the west Pacific warm pool by Chen and Houze (1997).

The time series of area covered by convection for Darwin (Fig. 8) has peaks at 1600 and 1900 CST. To 

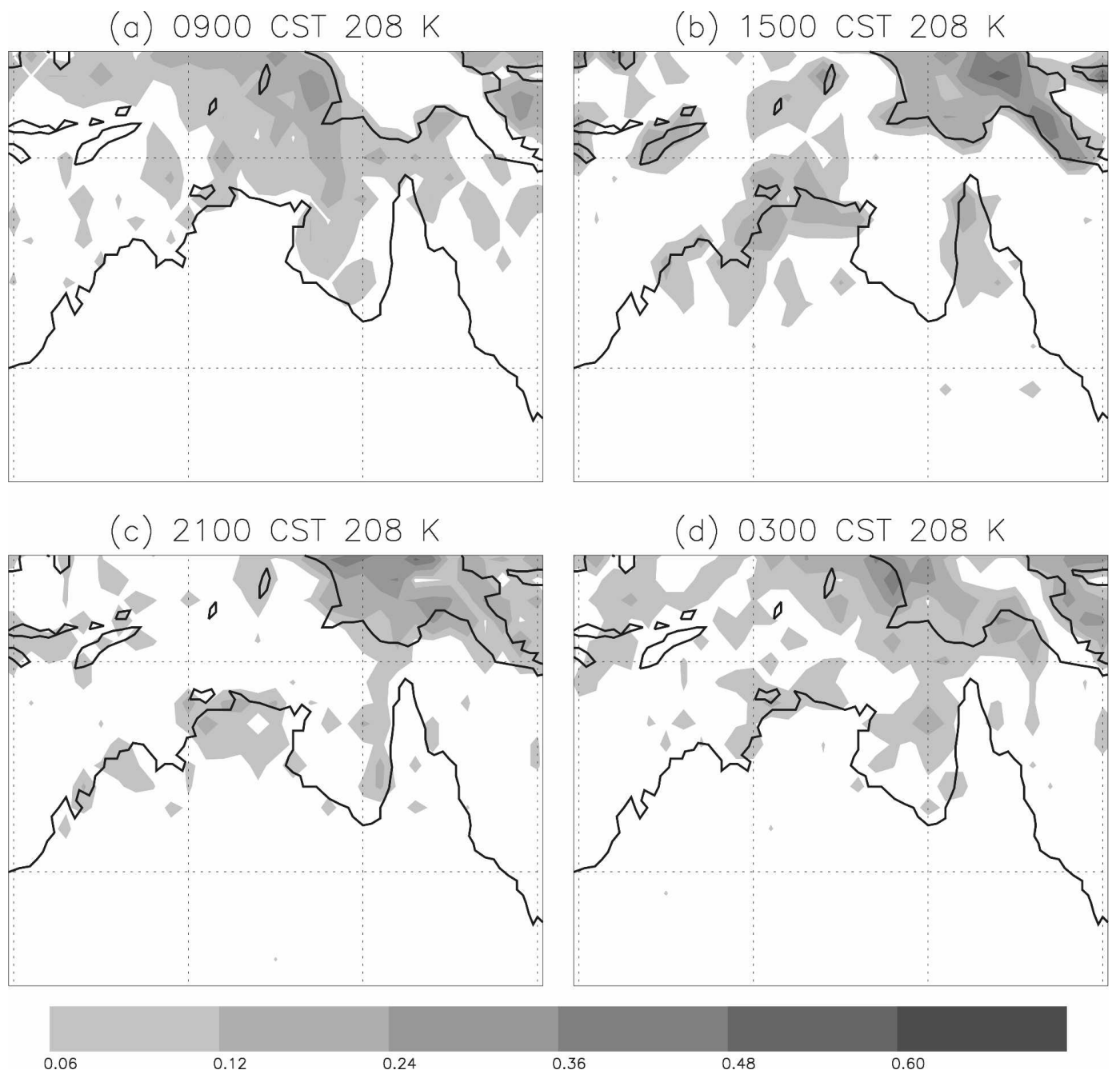

FIG. 7. The diurnal cycle of the geographical distribution of 208-K CEs per day at (a) 0900, (b) 1500, (c) 2100, and (d) 0300 CST at Darwin. Results are shown at a $1^{\circ} \times 1^{\circ}$ resolution.

examine this behavior further, the results are stratified according to the zonal component of the 700-hPa wind from the 0930 CST radiosonde flight in Fig. 9. The direction of the 700-hPa wind is a proxy for active monsoon (westerly component) and break monsoon (easterly component) periods. The diurnal cycle of the number of CEs (Fig. 9a) is slightly weaker (3\%-6.5\% range of total numbers) in the westerly wind environment compared to the easterly wind environment (approximate $3 \%-7.5 \%$ range of total), and the westerly environment peak is broader and earlier than the easterly environment peak. However, a two-sided KolmogorovSmirnov (KS) test indicates there are no significant differences between the two CE number distributions at a $5 \%$ significance level. Plots of both the mean percentage coverage of the Darwin region (Fig. 9b) and the mean CE size (Fig. 9c) show a unimodal distribution for the easterly environment with a peak near 2200 CST and bimodal distribution for the westerly environment with peaks near 1600 and 0400 CST. The mean size of the CEs is largest for the easterly environment (Fig. 9c). Figure 9d shows the probability distribution function of a $\mathrm{CE}$ having an equivalent radius $r(\mathrm{~km})$ at any time during the diurnal cycle, where $r=(\text { area of a } \mathrm{CE} / \pi)^{1 / 2}$. Equivalent radius is used as a measure of $\mathrm{CE}$ size (Machado and Rossow 1993). Although, on average, the largest CEs occur during the easterly regime at Darwin (Fig. 9c), the largest observed CEs are slightly more likely to occur during periods of westerly winds at 700 $\mathrm{hPa}$, which are associated with the active monsoon (Fig. 9d).

Comparison between mean $\mathrm{CE}$ areas for different regions (Fig. 9e) suggests that Darwin is more continental in character in during an easterly regime and 

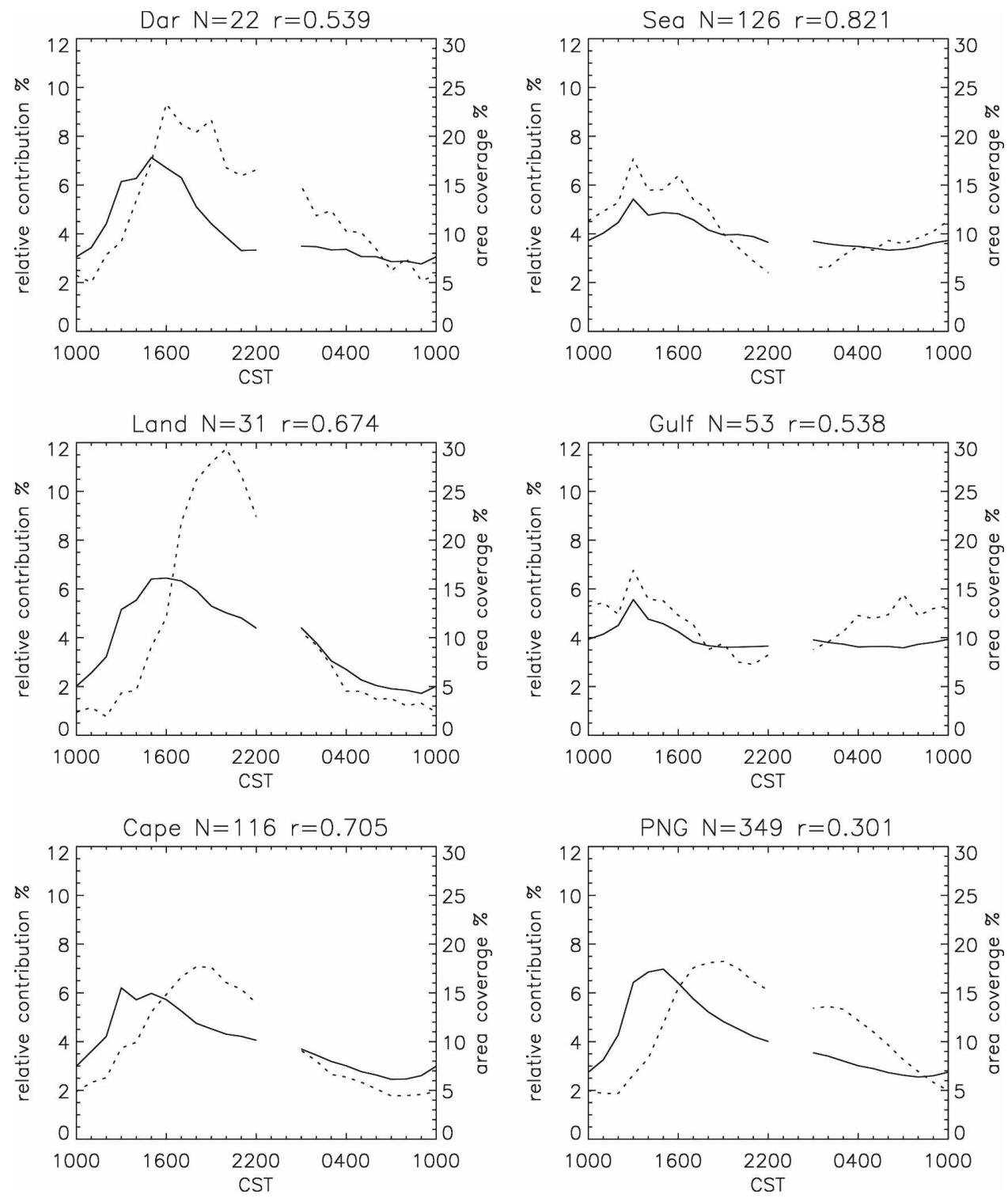

FIG. 8. The diurnal cycle of the relative contribution (\%) of convection for the regions surrounding Darwin (Dar), the Timor Sea (Sea), Arnhem Land (Land), the Gulf of Carpentaria (Gulf), Cape York Peninsula (Cape), and Papua New Guinea (PNG) to the total daily CE number at the 235-K threshold (solid line), binned every hour. See Fig. 1 for the areas indicated. Also shown (dotted line) is the percentage areal coverage of the indicated areas: $N$ is the average number of CEs day ${ }^{-1}, r$ is the correlation between number of CEs and areal coverage. The hours of 2400 and 0100 CST have been removed because approximately $38 \%$ of the images are missing at those times.

more maritime in character during a westerly regime. The diurnal cycle of mean CE area for Darwin under an easterly regime closely follows that for land. The diurnal cycle of the Darwin area during a westerly wind regime bears some similarities with the sea and gulf regions. All three regions have a much smaller diurnal variation than the land and easterly wind regime cycles, with a minimum in area coverage near 2200 CST, which is out of phase with land and Darwin during break pe- riods. The Darwin diurnal cycle is bimodal with peaks during the afternoon (1600 CST) and early morning (0400 CST). The sea region has a broad maximum from 1000 to 1600 CST. The Gulf of Carpentaria has a maximum in CE size near 0700 CST and a small peak near 1600 CST. It appears that the diurnal cycle of CE size during a westerly regime at Darwin is different to that during an easterly regime, but not entirely maritime in character. 
(a)

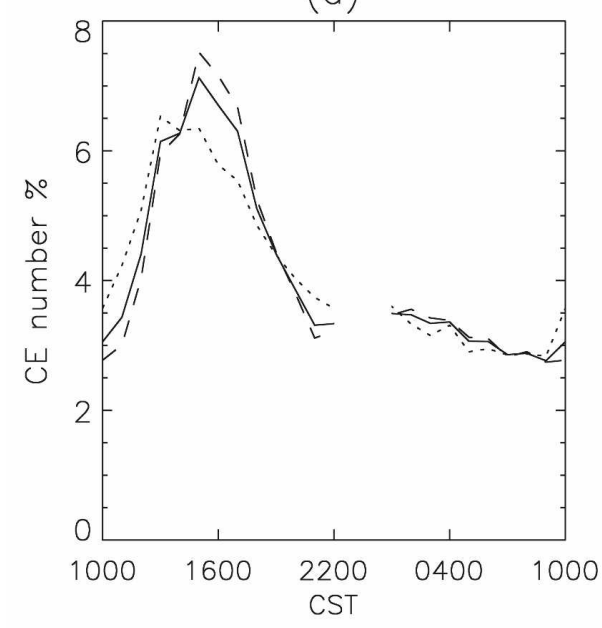

(c)

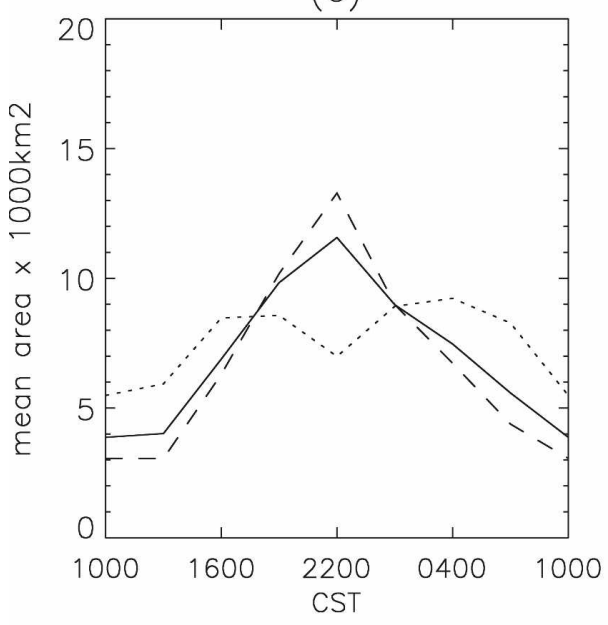

(e)

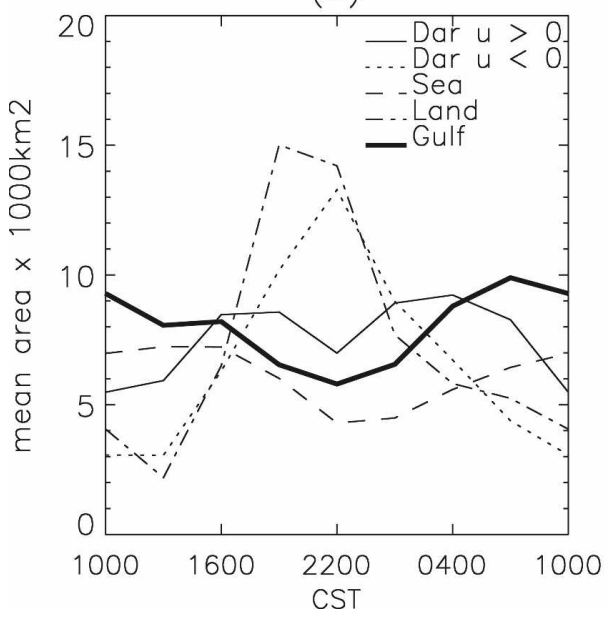

(b)

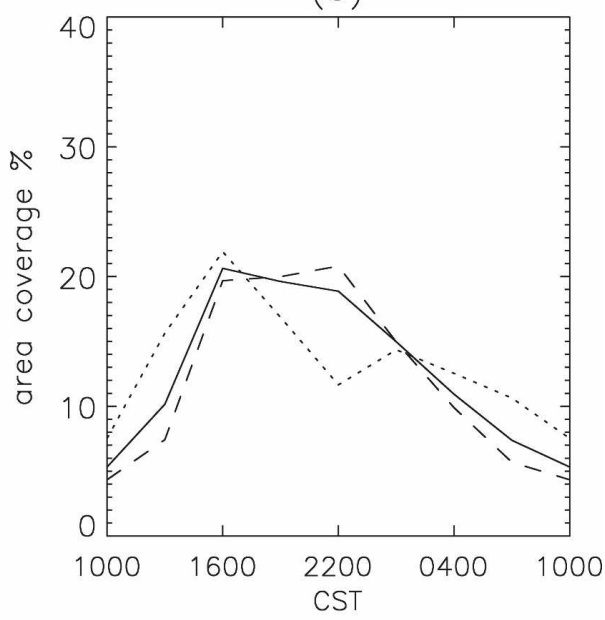

(d)

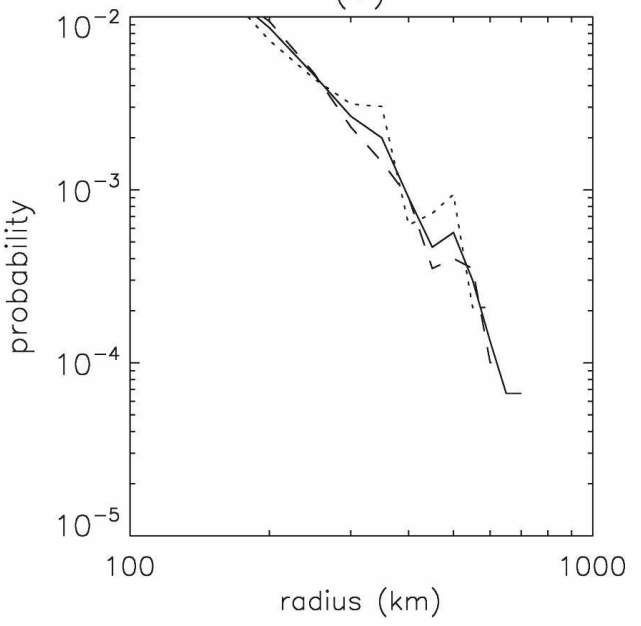

All CES

$u 700 \mathrm{hPa}>0$

u $700 \mathrm{hPa}<0$

FIG. 9. The diurnal cycle for CEs at the 235-K threshold at Darwin for the total number of CEs observed (solid line) and stratified by the 2300 UTC 700 -hPa zonal wind as westerly (dotted line) and easterly (dashed line). Shown are (a) percentage contribution to daily total CE number, (b) percentage area coverage of Darwin area (see Fig. 1), (c) mean CE area, (d) probability distribution function (pdf) of $\mathrm{CE}$ radii in 50-km bins, and (e) comparison of the mean CE area at the $235-\mathrm{K}$ threshold comparing Darwin with westerly $700-\mathrm{hPa}$ zonal winds as a proxy for active monsoon periods (solid line), Darwin with easterly 700-hPa zonal winds (dotted line), sea (dashed line), land region (dot-dashed line), and the Gulf of Carpentaria (heavy solid line). CE number is in 1-h bins; area coverage and mean area are in 3-h bins. 


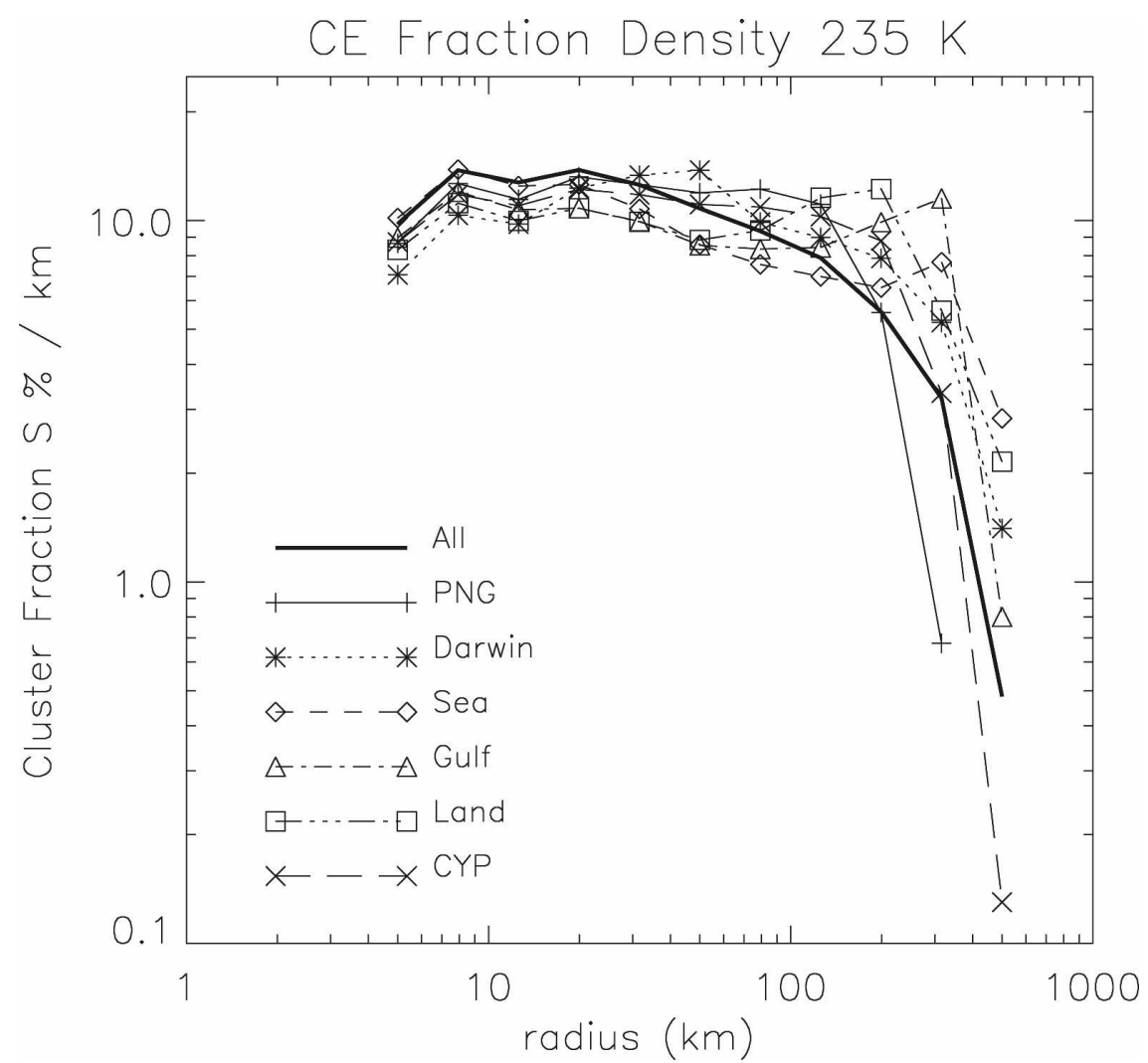

FIG. 10. CE fraction density $S(\Delta R)$ of the area covered by CEs with equivalent radius within a bin of size $\Delta R$, of the total area covered by all CEs, at the $235-\mathrm{K}$ threshold for the entire study area and various subregions shown in Fig. 1.

\section{c. CE size distribution}

Previous studies have found that the number distribution of CEs may be described as a simple power law, permitting a description of tropical convective cell organization at the mesoscale to subsynoptic scales (Machado et al. 1992). The power law is typically of the form $n(r) \propto r^{-d}$, where $d \sim 2$ (Machado et al. 1992; Machado and Rossow 1993). This implies that CEs of every radius contribute equally to the total observed cloudy area because $n(r) A(r) \propto r^{2-d} \propto$ constant, where $A(r)$ is the cloudy area of a CE with equivalent radius $r$. The CE distribution is observed to follow a power law up to an upper value of $r$, above which the distribution is much steeper. This upper value is referred to as the upper cutoff. This section examines distributions of CEs at two temperature thresholds to determine the robustness of these observed power laws. In the present study, the technique of Burroughs and Tebbens (2001) is used to obtain an accurate estimate of $d$ by fitting a power law to the cumulative number distribution, explicitly including the upper cutoff. By applying this technique to CEs in this study at the 235- and 208-K thresholds, values of $d$ of 2.0 and 1.85, respectively, were obtained. These results are in general agreement with the result of $d \sim 2$ of Machado and Rossow (1993) for 245-K CEs at local noon for January-February and July-August over the entire tropics. Further, the increase in the value of $d$ with increasing temperature thresholds is in agreement with Machado et al. (1992), who found that $d$ changed from 2.3 using a $253-\mathrm{K}$ threshold to 1.8 for a $218-\mathrm{K}$ threshold for CEs distributions over tropical Africa and the Atlantic Ocean. They concluded that the difference in slope was related to real differences in the morphological characteristics of the upper- and midlevel clouds. The increase in $d$ with increasing cloud-top temperature threshold indicates that the relative number of smaller clouds increases with increasing temperature.

The study of Machado and Rossow (1993) covered the region of the present study, but only considered how land-ocean differences affect the CE distribution. To examine spatial variability in the number of CEs, cluster fractions for CEs at the $235-\mathrm{K}$ threshold for the geographical subregions are calculated and shown in Fig. 10. The cluster fraction density $S(\Delta R)$ is defined as the contribution to the total cloudy area by CEs in a 


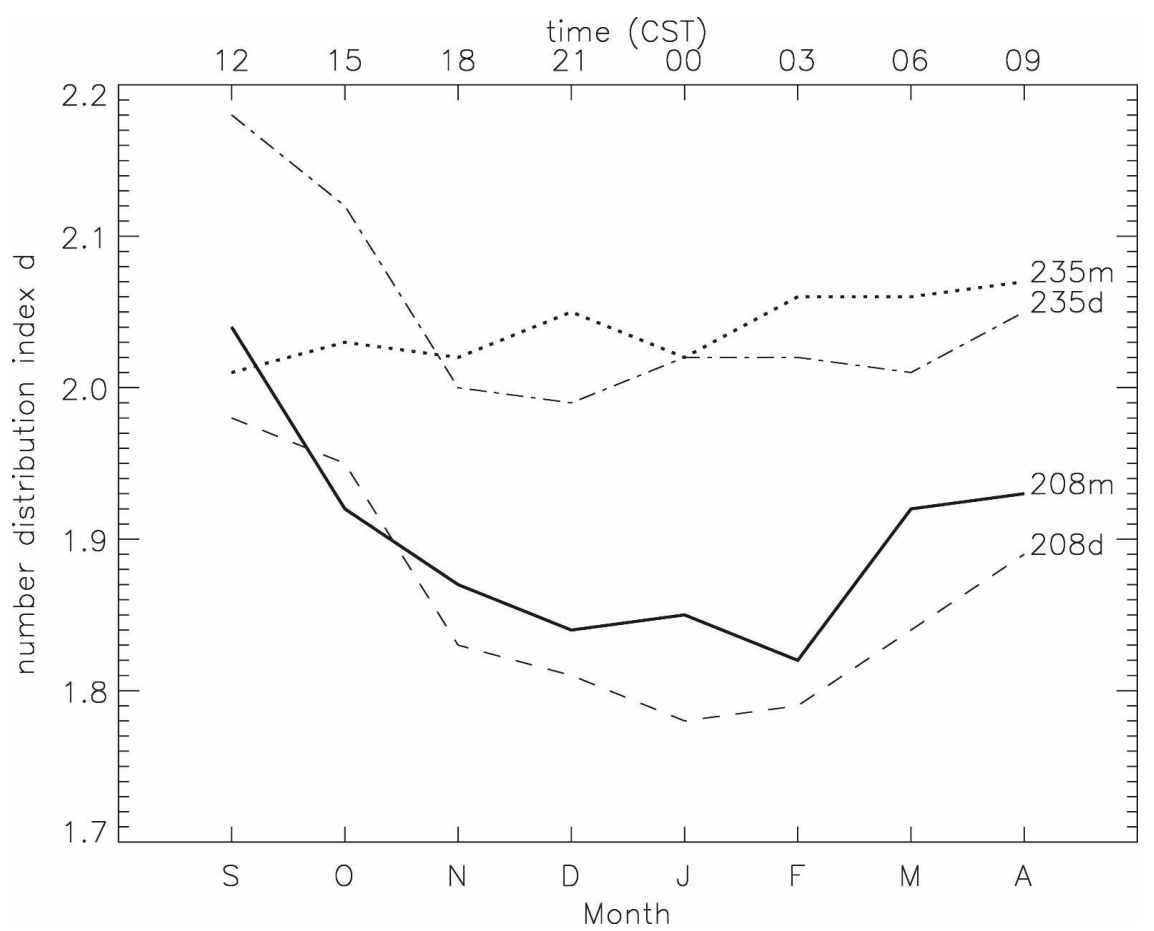

FIG. 11. The seasonal and diurnal cycles of the exponent $d$ of the number distribution $n(r) \propto r^{-d}$ of CEs or radius $r$ for two temperature thresholds for CE detection: 208 and $235 \mathrm{~K}$. The letter $\mathrm{m}$ indicates monthly variation and $\mathrm{d}$ indicates the diurnal variation.

radius bin of size $\Delta R=(c-1) R$, where $c=1.58$ corresponds to radius bins chosen in equal steps of 0.2 in $\log _{10}(R)$, and $R$ is the lower radius of the bin. The cluster fraction may be written as

$$
S(\Delta R)=\frac{1}{\Delta R S_{t}} \int_{R}^{c R} \pi r^{2} n(r) d r,
$$

where $S_{t}$ is the total cloudy area summed over all bins (Machado et al. 1992). If $d \sim 2$, then $S(\Delta R)$ will be flat up to the upper cutoff radius, above which the slope increases sharply. Below the cutoff, all radius classes contribute equally to the total observed cloudiness. The distribution for the entire study area is flat to approximately $50 \mathrm{~km}$ and then gently slopes away to around $123 \mathrm{~km}$, with the slope increasing more rapidly thereafter. The upper cutoff radius is clearer for each of the subregions, with the sea and gulf regions with cutoffs at about 307 km; Darwin, Arnhem Land, and Cape York Peninsula at around $194 \mathrm{~km}$; and PNG at about $122 \mathrm{~km}$. The significance of CEs near $300 \mathrm{~km}$ over the oceans is consistent with Machado and Rossow (1993), who found a large contribution to cloudy area in the radius range of $300-400 \mathrm{~km}$. Their results were for January and February, when the monsoon trough is active over waters north of Australia.

The $300-\mathrm{km}$ length scale is not related to the size of the boxes used for each region, because CEs are counted as part of that region if part of their cloudy area lies within the box. Mapes and Houze (1993) suggested that $300 \mathrm{~km}$ is the distance that ice particles in the stratiform region can travel from their parent convection before falling out. If this fallout or dissipation time is greater than the lifetime of the parent convective cell, the CE grows in time (Houze 2004). The maximum $\mathrm{CE}$ size is limited by the number of convective cells possible at any one time, known as the convective sustainability of the environment. Schumacher and Houze (2003) suggest that CE sizes are limited over the land because of the strong diurnal cycle of the boundary layer. At night, the boundary layer becomes stable, limiting the development of fresh convection. Over the oceans, the weaker diurnal cycle allows convection to continue overnight, allowing CEs to increase in size. Near the equator, the Rossby radius is large and likely does not affect CE size except in the case of strong middle-level vorticity associated with the deep convection (Houze 2004).

Seasonal changes in the slope $d$ of the CE distribution at the 235-K threshold are small (Fig. 11), although during December-February the largest CEs total mean monthly numbers at this threshold were observed. Seasonal variations in $d$ at the $208-\mathrm{K}$ threshold are larger, 
with $d \sim 2.0$ during September and $d \sim 1.8$ during February, which is a change of about $11 \%$. This suggests that small, cold CEs are most significant early in the monsoon season when isolated continental convection dominates. By February, the monsoon trough is active over the Maritime Continent, generating large oceanic MCS (Liu et al. 2007). The effect of maritime MCSs is to decrease $d$, flattening the size distribution of the CEs.

A major characteristic of continental tropical convection is its response to the diurnal cycle. It is found here that the exponent $d$ varies diurnally, reaching a maximum value of about 2.0 (steepest) at 1200 CST and a minimum value of 1.8 (flattest) at 0000 CST for $208-\mathrm{K}$ CEs (Fig. 11). The diurnal cycle of $d$ is weaker for 235-K CEs, with a maximum value of 2.18 at 1200 CST. The most intense convection forms over the continents (Zipser et al. 2006) and hence the 208-K diurnal cycle most likely reflects the development of small continental CEs during the day. Larger CEs form as convection becomes more organized during the afternoon. CEs at the $235-\mathrm{K}$ threshold are more evenly distributed over land and ocean and hence the overall area diurnal cycle is flat, containing an afternoon/evening continental peak and overnight/morning oceanic peak. These results are broadly consistent with Machado et al. (1992) for tropical Africa. They found that the CE distribution was dominated by the continental diurnal cycle. The largest CEs occurred during the afternoon at 1500-1800 CST, with the slope in CE distribution also varying diurnally.

\section{MCS tracking}

While the statistics of the CEs presented in the previous section gives insight into the seasonal, diurnal, and geographical variation of convection over northern Australia and the adjacent waters, the analysis is limited to snapshots of the cloud field at particular times. As discussed in section $3 b$, MCSs are defined as cloud systems with areas at least $5000 \mathrm{~km}^{2}$ for a period of at least $2 \mathrm{~h}$. Once defined, it is possible to track systems throughout their life cycle. A climatology of MCSs is presented in the following subsections. This dataset contains 26458 MCSs at the $235-\mathrm{K}$ threshold and 13585 MCSs at the 208-K threshold.

\section{a. Geographical distribution}

Plots of the geographical distribution of MCSs (not shown) are broadly similar to those shown in Figs. 3 and 4 for the CEs. One key difference is that the differences in the number of MCSs over PNG during February between the two temperature thresholds are not as large as those shown seen in Figs. 3 and 4 for the CE numbers. The number of MCSs shows a slight increase at the 208-K threshold over PNG during February compared to October, rather that the decrease shown for the CEs. This suggests that the decrease in 208-K CE numbers during February over PNG implies a shift in the size distribution to fewer and larger 208-K CEs, reflected in a larger detection of MCSs that have a minimum size of $5000 \mathrm{~km}^{2}$ compared to the CE minimum size of $75 \mathrm{~km}^{2}$.

\section{b. Diurnal cycle}

To study the diurnal cycle using system tracking, first MCS genesis and decay are identified. MCS genesis is defined to be the first time at which the areal extent of the cloud system is at or above the $5000 \mathrm{~km}^{2}$ threshold. Decay is the time of last at which appearance of the MCS satisfies the minimum size threshold. Figure 12 shows the diurnal cycle of genesis and decay in the various subregions for MCSs at the $235-\mathrm{K}$ threshold. All of the land-based locations have a strong peak in the genesis near $1500 \mathrm{CST}$, which is similar to that for the number of CEs (cf. Fig. 8). This implies that a significant number of the CEs studied earlier form the early stages of MCSs for those regions. A weaker nocturnal peak near 0300 CST is discernable also. The afternoon peak is sharpest for Darwin and broadest for the inland Top End. The afternoon genesis maximum is followed by a decay peak approximately $3 \mathrm{~h}$ afterward at Darwin and 6-7 $\mathrm{h}$ later for the other continental regions. For the Timor Sea and Gulf of Carpentaria, the diurnal cycle is weaker, with daytime peaks in the genesis of MCSs at about 1300 CST over the Gulf of Carpentaria and 1500 CST in the Timor Sea, with a nocturnal peak at 0300 CST. Results for genesis and decay are similar for the 208-K threshold (not shown).

As previously for the CE statistics, it is instructive to distinguish the diurnal cycle at Darwin stratified by wind regime. The times of genesis and decay at Darwin are stratified according to the sign of the 700-hPa zonal wind at 0930 CST and are shown in Fig. 13. The results are grouped into 3-h bins resulting from the smaller sample sizes after stratifying the observations. There is a prominent peak in MCS genesis at 1600 CST during both wind regimes, followed by a peak in MCS decay 3 $\mathrm{h}$ later. However, the afternoon genesis and decay peaks are less significant during the active monsoon. The close relationship between genesis and decay during the afternoon suggests that the mean MCS lifetime is close to $3 \mathrm{~h}$. During the westerly regime, a secondary nighttime genesis peak emerges at 0100 CST. As was the case for CEs, MCS stratification for Darwin is con- 
MCS start/end time $235 \mathrm{~K}$
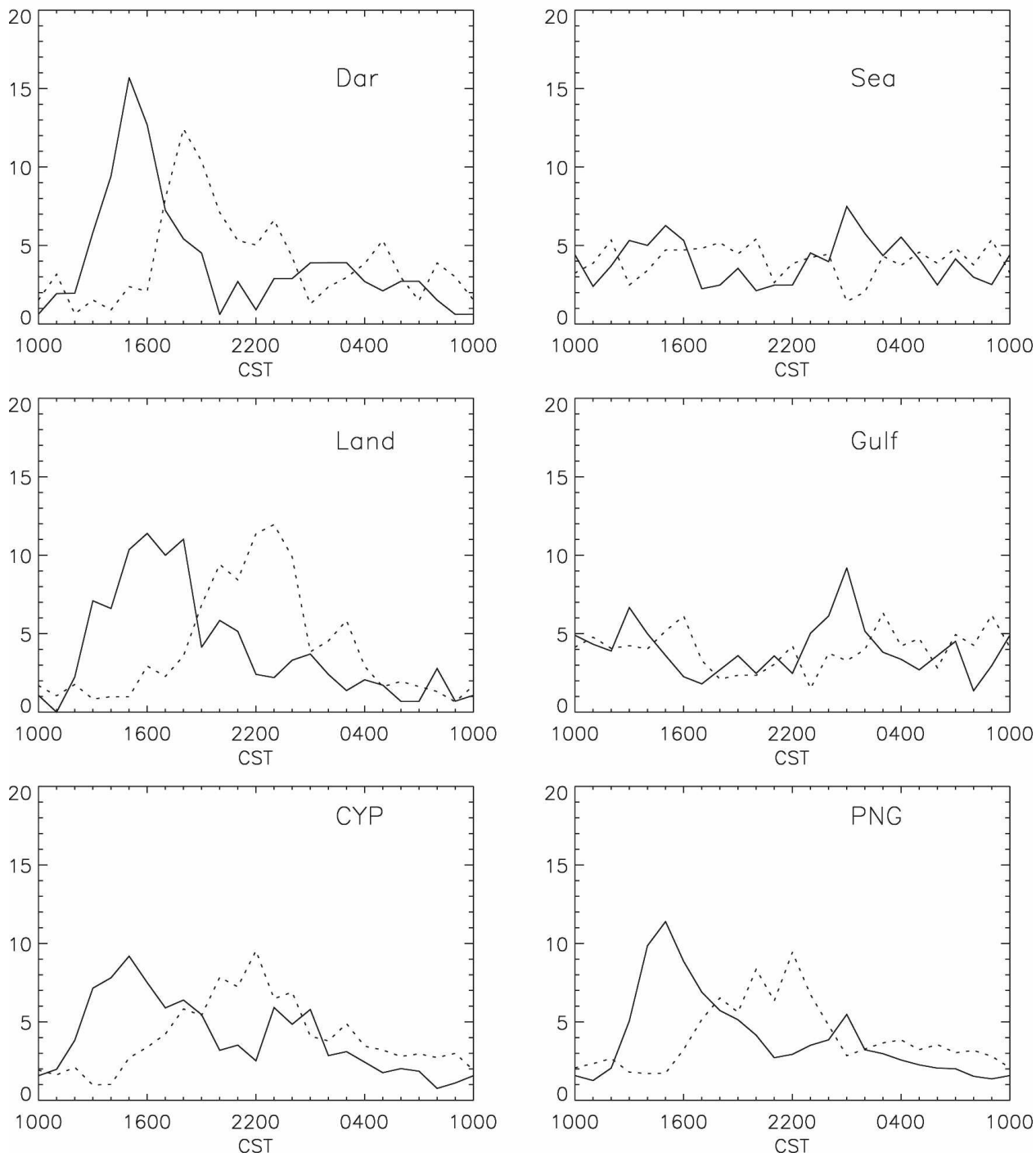

FIG. 12. The diurnal cycle of genesis (solid) and decay (dashed) of MCS at the 235-K threshold for the different subregions shown in Fig. 1.

sistent with a maritime influence during westerly winds at $700 \mathrm{hPa}$, which is a proxy for an active monsoon environment.

\section{c. Life cycle}

Figure 14 shows the mean evolution of MCS equivalent radius and the minimum single pixel temperature, grouped in 1-h lifetime bins. As the lifetime of the MCSs increases, the maximum size attained increases and the lowest pixel temperature decreases, on average. The relationship between mean maximum equivalent radius and the MCS lifetime is approximately linear, in agreement with Chen et al. (1996, their Fig. 14). How- ever, as the variance increases with increasing lifetime, the lifetime is not an unequivocal predictor of maximum size, as shown in Fig. 15. Figure 15a shows the relationship between lifetime and maximum size for MCSs that merge during their lifetimes. Previous studies (Machado and Laurent 2004) have typically excluded mergers from their calculations. Mergers were included in the present study because they are common (26\% of the $235-\mathrm{K}$ MCSs and $21 \%$ of the $208-\mathrm{K}$ MCSs in this dataset) and contribute to the lifetime of longlived MCSs. For a given lifetime there is a large variance in maximum size. Also shown in Fig. 14 is the average time evolution of MCSs with lifetimes of 24, 30, 

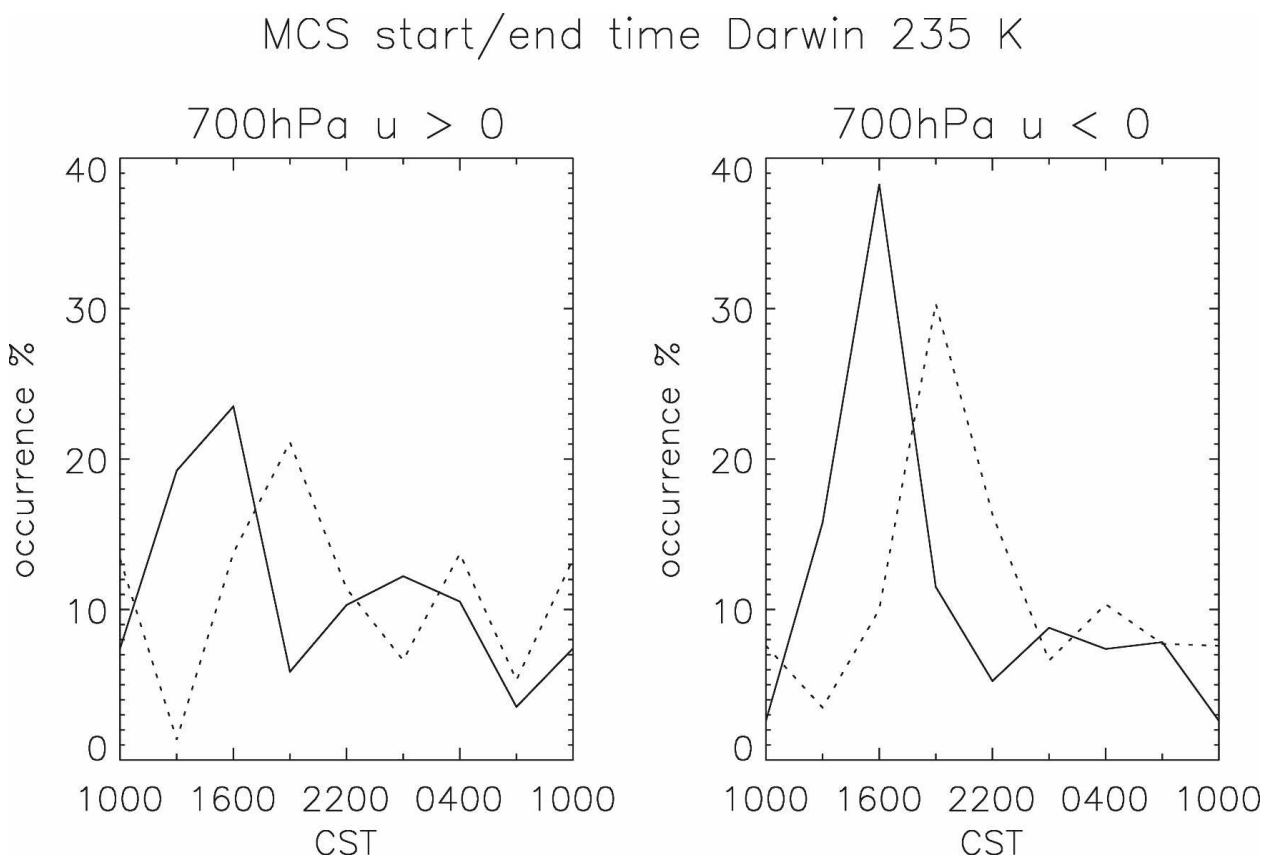

FIG. 13. The diurnal cycle of genesis (solid) and decay (dashed) of MCSs at the 235-K threshold for Darwin, stratified by the 2300 UTC 700-hPa zonal wind as (left) westerly and (right) easterly. Results are binned every $3 \mathrm{~h}$.

36,42 , and $48 \mathrm{~h}$. Smaller sample size $(31,15,11,5$, and 8 respectively) introduces sampling errors. However, the results indicate that beyond $24 \mathrm{~h}$ the time of maximum size does not occur during the midpoint of MCS evolution, and there is no relationship between lifetime and maximum size. Variations in size may be related to radiative effects [see Chen and Houze (1997) for a review of different mechanisms] and mergers.

Figure 15b shows the relationship between lifetime and maximum size for MCSs, excluding mergers during their lifetimes. The variance in maximum size for a given lifetime is still large, but has decreased compared to the case where mergers are included such that few MCSs reach a size $>300 \mathrm{~km}$. Removal of mergers removed all MCSs with lifetimes beyond about 1 day (Figs. 15b and 16), consistent with the results of Kondo et al. (2006). The changes in variance and mean maximum radius suggest that mergers are unimportant for the shortest-lived MCSs, affect the development of intermediate lifetime MCSs, and appear to be essential for long-lived MCSs.

The maximum size attainable, and hence lifetime, is dictated by the rate at which new cells form versus the dissipation of stratiform regions. During the mature and dissipative phases, the MCS cloudy area will consist of a larger proportion of stratiform cloud, although use of IR data alone cannot provide this information. Houze (2004) suggested that the diurnal cycle of the boundary layer over land inhibits MCSs reaching the largest sizes by reducing the thermodynamic sustainability of the boundary layer to the development of new convective cells. The results presented here support his suggestion, with a sharp afternoon peak in continental $\mathrm{CE}$ area coverage followed by a rapid drop-off near sunset. Over the oceans, Houze (2004) contends that a weak diurnal cycle implies that MCSs can increase in size regardless of time of day. This study suggests that CEs increase in size preferentially overnight and morning (Fig. 8), although the results are not significant enough to be conclusive.

Figure $14 \mathrm{~b}$ shows the evolution of minimum pixel temperature with time. The minimum pixel temperature occurs approximately half way through the MCS's lifetime, which is about the time at which the equivalent radius is a maximum. In general, the longest-lived MCSs tend to be the largest systems, reaching the largest sizes in the mature phase of their lifetime, and display the lowest pixel temperature observed during their lifetime. Plots of mean lifetime minimum temperature versus lifetime (not shown) indicate that the lifetime minimum temperature is not linearly related to lifetime, with a large temperature range for each lifetime class. The variance decreases with increasing lifetime. The standard deviation in lifetime minimum temperature for MCSs at the 208-K threshold with lifetimes of $6 \mathrm{~h}$ is $10 \mathrm{~K}$, and for $24-\mathrm{h}$ lifetimes is $3.5 \mathrm{~K}$. 
(a) life $\leqq 24 \mathrm{hrs} 235 \mathrm{~K}$

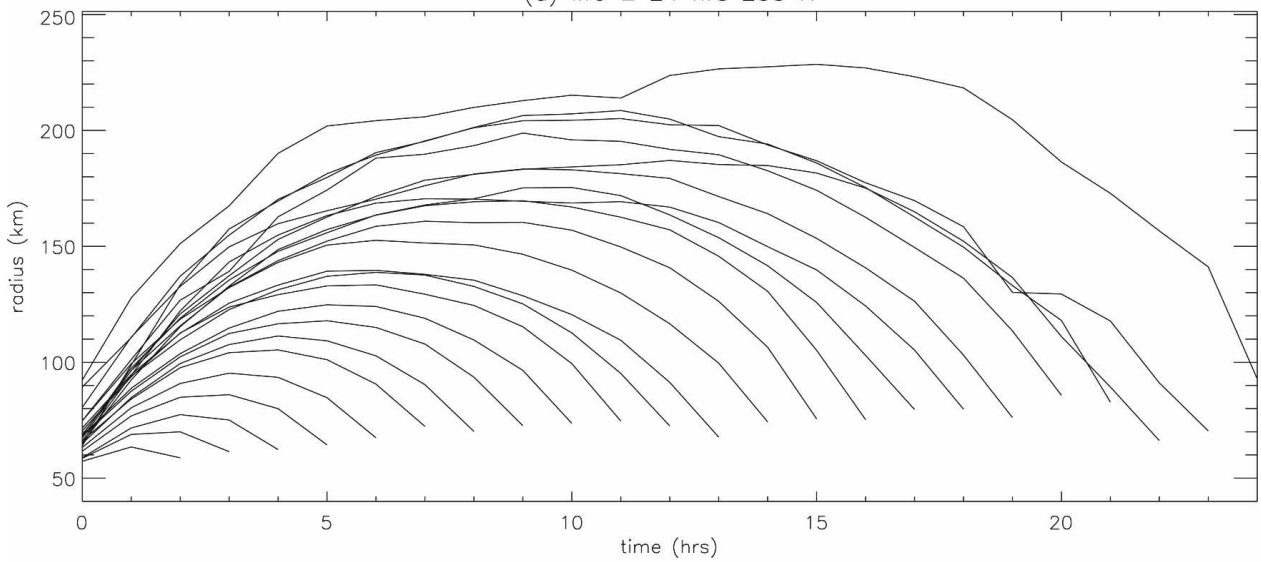

(b) life $\leqq 24 \mathrm{hrs} 235 \mathrm{~K}$

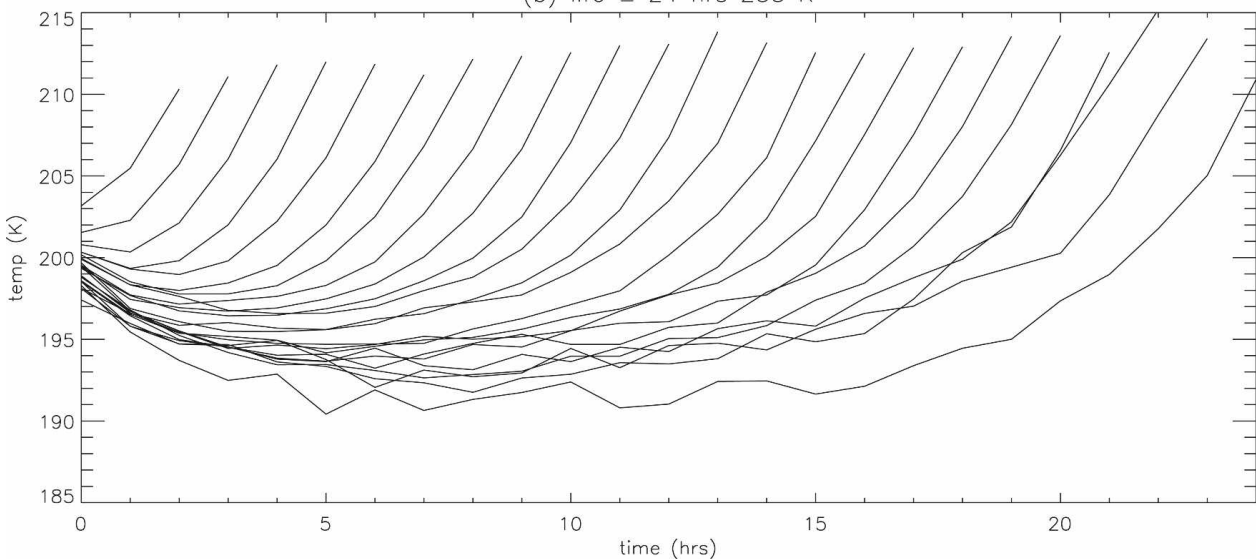

(c) $24 \leqq$ life $\leqq 48$ hrs $235 \mathrm{~K}$

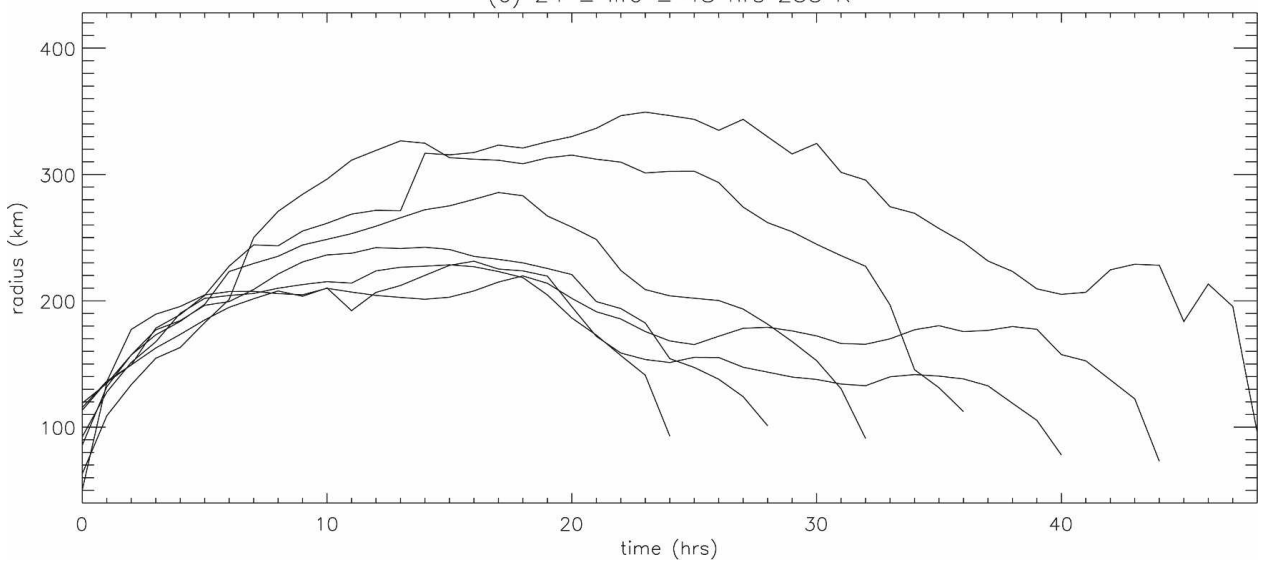

FIG. 14. The average lifetime evolution of MCS for the 235-K threshold, for 1-h lifetime bins from 2-24-h (a) equivalent radius vs time and (b) minimum pixel temperature vs time. (c) Also shown is the equivalent radius vs time for lifetimes of $24,30,36,42$, and $48 \mathrm{~h}$.

In contrast, Kondo et al. (2006) claimed that the minimum temperature occurred early in a MCS's lifetime. However, they employed a minimum speedtracking algorithm compared to the areal overlap technique used in the present study, allowing for a smaller minimum MCS size, and thereby capturing the initial development of deep convection. Further, their analysis was limited to MCSs with lifetimes in the range of 2-6 $\mathrm{h}$, and shows a trend toward the lifetime minimum temperature during the mature phase for their longer-lived 
(a) Mergers included $235 \mathrm{~K}$

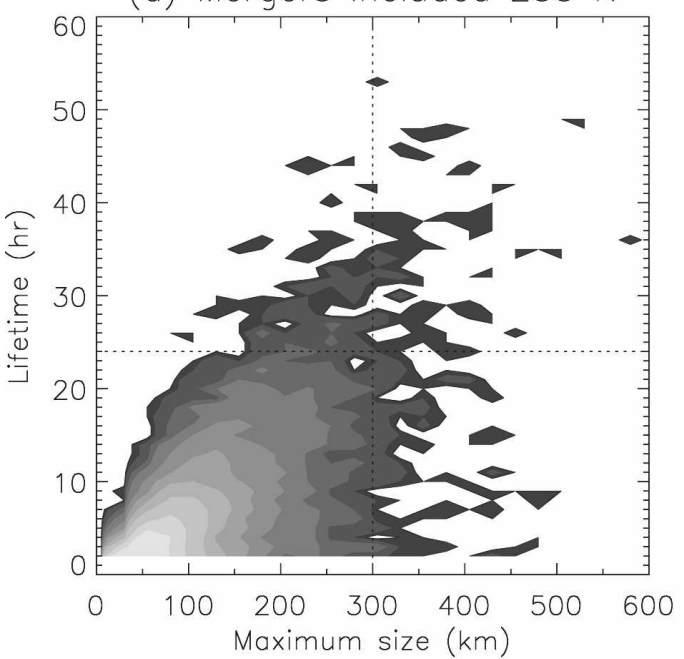

(b) No mergers $235 \mathrm{~K}$

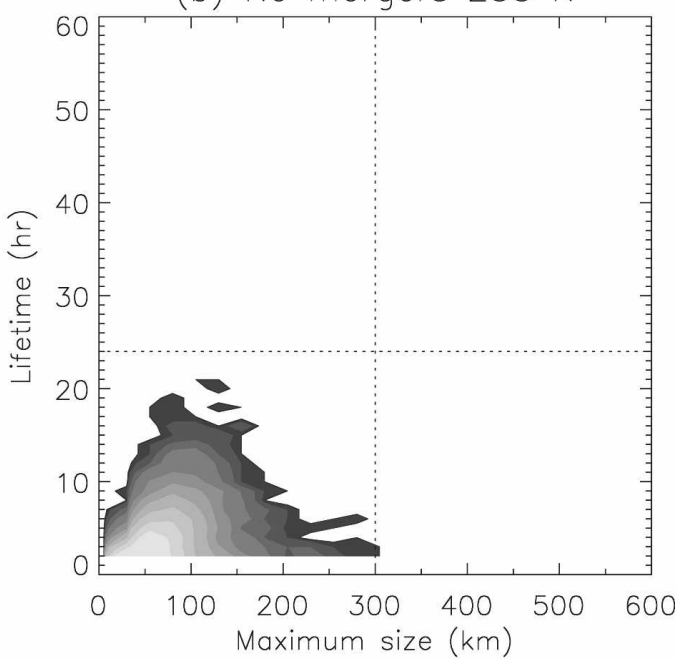

FIG. 15. The relationship between MCS lifetime and the maximum equivalent radius achieved for systems identified at the 235-K threshold. Results shown are for (a) MCSs that merge during their lifetime and (b) MCSs that do not merge. The horizontal dotted line marks lifetimes of $24 \mathrm{~h}$, the vertical line is radii of $300 \mathrm{~km}$.

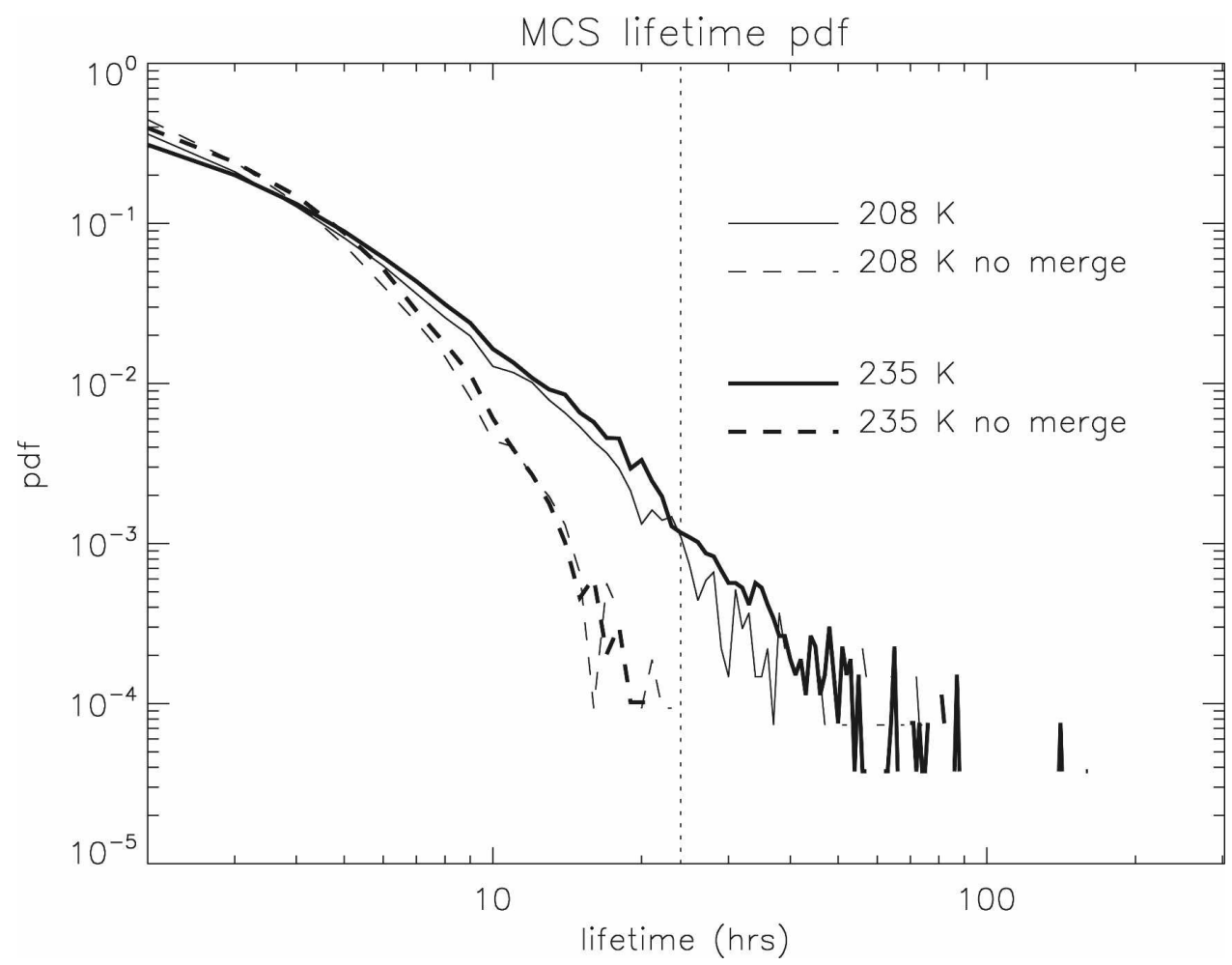

FIG. 16. Probability distribution function of MCS lifetime for 235- (thick lines) and 208-K (thin lines) MCSs with (solid lines) and without (dashed lines) mergers. A lifetime of 1 day is indicated by the vertical dashed line. 
MCSs. Figure 14b shows that for the longer-lived MCS, the minimum pixel temperature decreases slowly with time. During this period, the areal increase is likely associated with the growth of the anvil. After this mature phase, the size decreases and minimum pixel temperature increases as deep convection ceases and the stratiform regions slowly dissipate.

The distribution of the lifetimes of MCSs is shown in Fig. 16. As in previous studies, it is found to follow a power law (Machado et al. 1998). The exclusion of mergers limits life to about 1 day (Kondo et al. 2006), with the inclusion extending the maximum observed lifetime to $\sim 3$ days for 208-K MCSs and approximately 5 days for $235-\mathrm{K}$ MCSs. The power-law exponents are 2.3 for 235-K MCSs and 2.5 for 208-K MCSs with mergers, and 2.8 and 2.9 , respectively, when mergers are excluded. The distribution is steeper without mergers as the contribution by longer-lived MCS is reduced.

\section{d. Area expansion}

The expansion of the area of a MCS over the first hour after genesis has been suggested as a useful shortterm indicator of the lifetime of the MCS (Machado and Laurent 2004). Figure 17a shows the normalized areal expansion in 1-h lifetime bins for lifetimes of 2-24 $\mathrm{h}$ for $235-\mathrm{K}$ MCSs. The bars indicate \pm 1 standard deviation. Following Machado and Laurent (2004), the expansion-lifetime relationship is fitted to the curve $A_{e}=A_{\text {asy }}-A e^{-\alpha T}$, where $A$ is a constant, $T$ is the MCS lifetime, $A_{\text {asy }}$ is the asymptotic median expansion rate for large lifetimes, and $\alpha$ measures how quickly the expansion rate approaches the asymptotic value. Large values in $\alpha$ imply little utility in $A_{e}$ for forecasting MCS lifetime. The parameter $\alpha$ is larger for $208 \mathrm{~K}$ than $235 \mathrm{~K}$ and for the expansion rate periods longer than the first hour. The utility of the initial expansion rate is shown in Fig. 17b. The probability distribution function of normalized expansion rate is plotted for the lifetime classes of $2-3,4-6,7-8,9-11,12-14$, and $15-17 \mathrm{~h}$. There is a shift in the peak of the probability distribution function for increasing lifetime, in agreement with the results of Machado and Laurent (2004), with decreasing discrimination between lifetime classes for increasing lifetime. The poor relationship discrimination between expansion rate and lifetime greater than $11 \mathrm{~h}$ is possibly due to the role of mesoscale convective vortices as convection becomes organized (Houze 2004).

\section{Conclusions}

The aim of this study was to use IR data to document the seasonal and life cycles and statistical characteristics of convection over northern Australian during the transition and wet seasons. This is the first multiyear study to use IR data to examine the details of the Australian monsoon. The seasonal cycle of cloud numbers follows changes in the global circulation and tropospheric moisture, as illustrated by composite aerological diagrams for Darwin. The largest CEs were observed during the peak of the monsoon (December-February) when the monsoon trough is located over northern Australia and the adjacent waters.

The diurnal cycle of the number of CEs confirms the results of previous studies that convective activity over the continents is tied closely to daytime surface heating, and most probably convergence associated with the sea breeze. The number of CEs over land peaks during the early afternoon, although the cloudy area reaches its maximum extent several hours later as the cloud systems become organized. Maritime convective activity has a weak early afternoon peak in CE numbers and a late-morning size maximum. Coastal convective activity, particularly in the bays around PNG, exhibits a nocturnal maximum in the number and size of the CEs.

Particular emphasis was placed on Darwin because it experiences alternating periods of active and break monsoon conditions. The diurnal cycle over Darwin during active monsoon conditions reveals a nocturnal MCS genesis peak and increase in CE size. During break period conditions, the diurnal cycle of CE size and number and MCS genesis and decay resemble those of other continental areas. The implication is that Darwin represents a useful location from which to study in detail the convection of the Maritime Continent as a whole.

The study of the life cycle of MCSs showed that the maximum size and minimum lifetime pixel temperature are reached during the midpoint of its lifetime (Machado et al. 1998). Kondo et al. (2006) found the minimum lifetime temperature to occur early in the lifetime of the MCS using the minimum speed-tracking technique that permitted a smaller minimum size than for the area overlap-tracking technique used in the present study. Rather than capturing the initial deep overshooting convection, this study shows that the mature stage of convection produces a large cloudy area with deep organized convection. In agreement with Kondo et al. (2006), this study shows that minimum pixel temperatures decrease slowly during the mature phase, where size is a maximum, consistent with growth in area resulting from anvil formation. However, use of the IR alone cannot determine how much of the cloudy area is due to thick cirrus and how much is due to deep convective updrafts.

The lifetime and maximum equivalent radius of an 
(a) $235 \mathrm{~K}$ expansion rate pdf

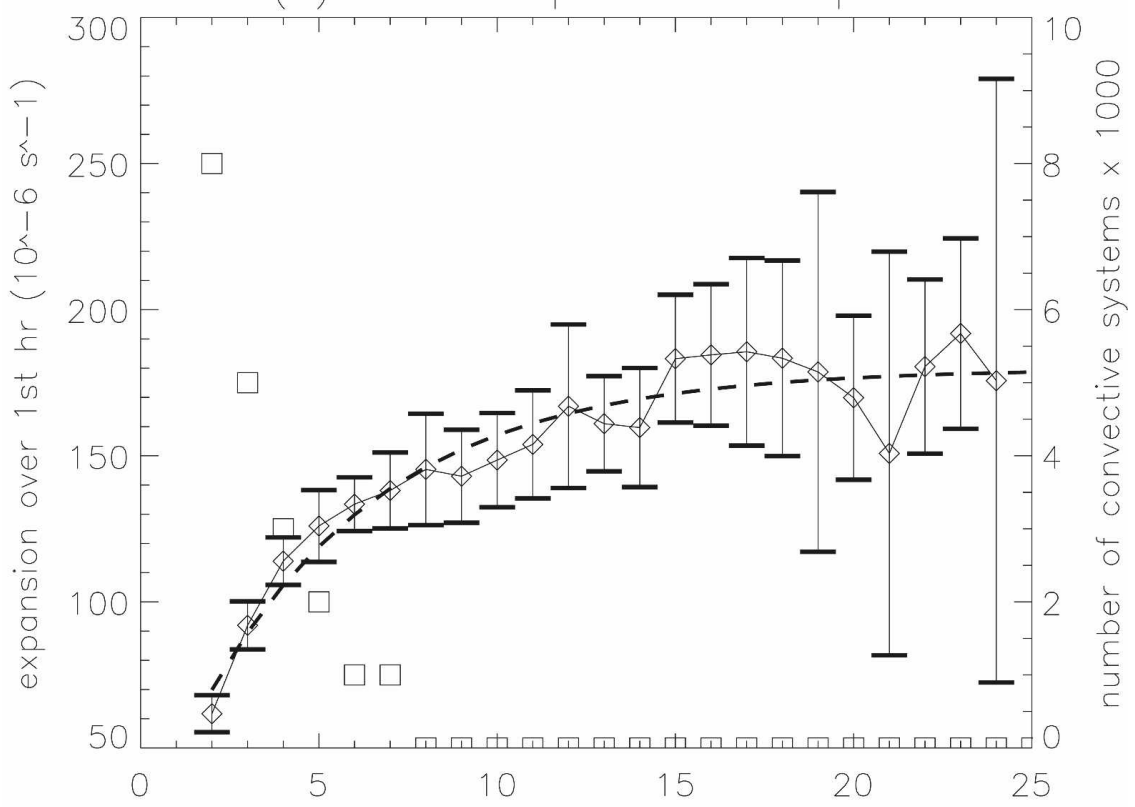

(b) $235 \mathrm{~K}$ lifetime vs expansion rate

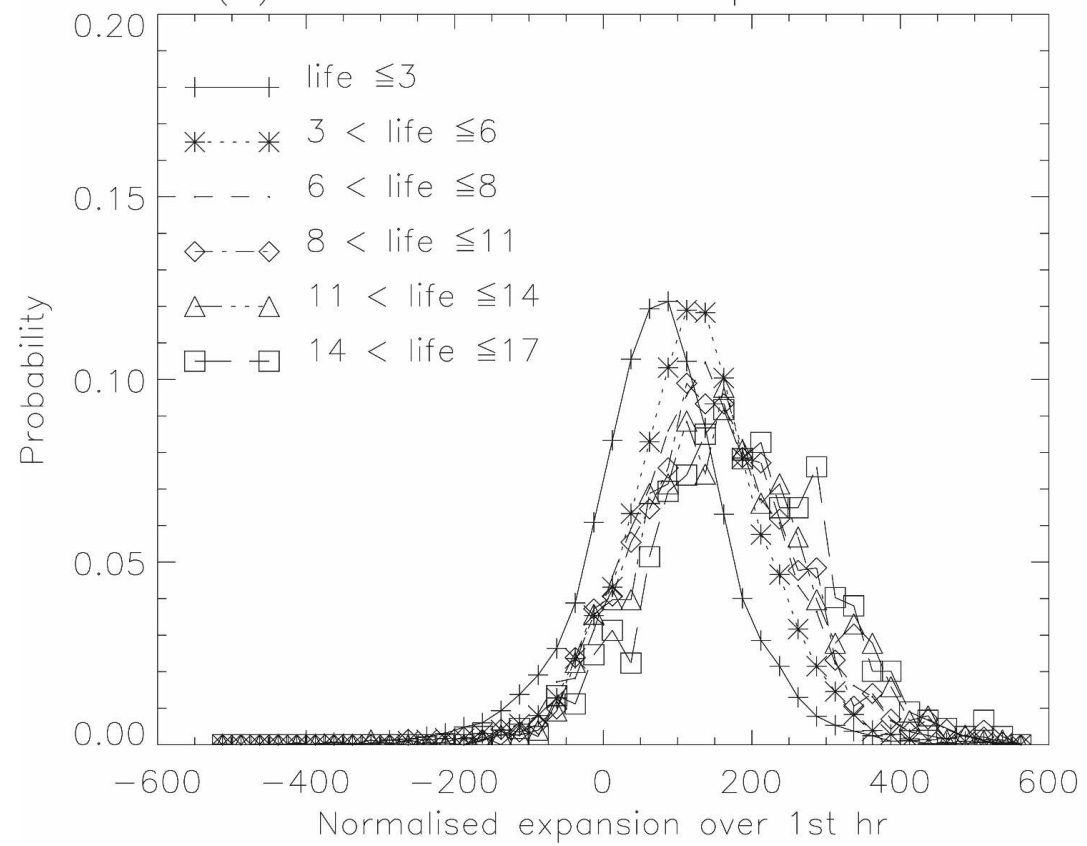

FIG. 17. (a) The areal expansion $\left(A_{e} ; 10^{-6} \mathrm{~s}^{-1}\right)$ (diamonds) and its standard deviation (bars) as a function of convective system lifetime (h) for $235-\mathrm{K}$ clusters over the first hour. The dashed line is a fit to the mean over the first $24 \mathrm{~h}$. The number of cases for each lifetime class is overlain (squares and right axis). (b) Probability distribution functions of expansion rate over the first hour of the lifetime of a cluster for the classes: $\leq 3 \mathrm{~h}, 3<$ lifetime $\leq 6 \mathrm{~h}, 6<$ lifetime $\leq 8 \mathrm{~h}, 8<$ lifetime $\leq 11 \mathrm{~h}, 11<$ lifetime $\leq 14 \mathrm{~h}$, and $14<$ lifetime $\leq 17 \mathrm{~h}$ for $235 \mathrm{~K}$.

MCS are approximately linearly related, in agreement with Machado et al. (1998). The initial expansion rate of the cloudy area is a potential predictor of MCS lifetime for short lifetimes (cf. Machado and Laurent
2004), because lifetime will be determined largely by the dissipation time of the stratiform regions resulting from the initial pulse of convection. Mergers are critical for MCS lifetimes greater than about 1 day. In general, 
longer-lived MCS attain lower minimum temperatures and larger maximum radii, and initially expand more rapidly than short-lived MCSs.

One of the defining characteristics of the monsoon over northern Australia is the alternating westerly and easterly wind regimes, referred to as active and break monsoon periods. In a companion paper (Pope et al. 2008, manuscript submitted to J. Climate), the MCS dataset developed here will be used to examine the differences between convection in these two environments.

Acknowledgments. The authors thank Brian Mapes of the University of Miami and Robert Rabin of the Space Science and Engineering Center, University of Wisconsin-Madison for supplying code for cloud identification and tracking. They also thank the three anonymous reviewers for helping improve the clarity of the manuscript. Mick Pope also acknowledges the support of a Bureau of Meteorology Scholarship.

\section{REFERENCES}

Ackerman, T. P., and G. M. Stokes, 2003: The Atmospheric Radiation Measurement Program. Phys. Today, 56, 38-44.

Arkin, P. A., 1979: The relationship between fractional coverage of high cloud and rainfall accumulations during GATE over the B-scale array. Mon. Wea. Rev., 107, 1382-1387.

Arnup, S. J., and M. J. Reeder, 2007: The diurnal and seasonal variation of airmass boundaries in the Australian region. Mon. Wea. Rev., 135, 2995-3008.

Burroughs, S. M., and S. F. Tebbens, 2001: Upper-truncated power laws in natural systems. Pure Appl. Geophys., 158, $741-757$.

Carbone, R. E., J. W. Wilson, T. D. Keenan, and J. Hacker, 2000: Tropical island convection in the absence of significant topography. Part I: Life cycle of diurnally forced convection. Mon. Wea. Rev., 128, 3459-3480.

Chappel, L.-C., 2001: Assessing severe thunderstorm potential days and storm types in the tropics. Proc. Int. Workshop on the Dynamics and Forecasting of Tropical Weather Systems, Darwin, Australia, Bureau of Meteorology, 55-65.

Chen, S. S., and R. A. Houze, 1997: Diurnal variation and lifecycle of deep convective systems over the tropical Pacific warm pool. Quart. J. Roy. Meteor. Soc., 123, 357-388.

,-- , and B. E. Mapes, 1996: Multiscale variability of deep convection in relation to large-scale circulation in TOGA COARE. J. Atmos. Sci., 53, 1380-1409.

Drosdowsky, W., 1996: Variability of the Australian summer monsoon at Darwin: 1957-1992. J. Climate, 9, 85-96.

_ , and G. J. Holland, 1987: North Australian cloud lines. Mon. Wea. Rev., 115, 2645-2659.

Goler, R., M. J. Reeder, R. K. Smith, H. Richter, S. Arnup, T. Keenan, P. May, and J. Hacker, 2006: Low-level convergence lines over northeastern Australia. Part I: The north Australian cloud line. Mon. Wea. Rev., 134, 3092-3108.
Houze, R. A., Jr., 2004: Mesoscale convective systems. Rev. Geophys., 42, RG4003, doi:10.1029/2004RG000150.

Keenan, T. D., and R. E. Carbone, 1992: A preliminary morphology of precipitation systems in tropical northern Australia Quart. J. Roy. Meteor. Soc., 118, 283-326.

_, J. McBride, G. Holland, N. Davidson, and B. Gunn, 1989: Diurnal variations during the Australian Monsoon Experiment (AMEX) phase II. Mon. Wea. Rev., 117, 2535-2552.

—, K. Glasson, F. Cummings, T. S. Bird, J. Keeler, and J. Lutz, 1998: The BMRC/NCAR C-band polarimetric (C-POL) radar system. J. Atmos. Oceanic Technol., 15, 871-886.

Kondo, Y., A. Higuchi, and K. Nakamura, 2006: Small-scale cloud activity over the Maritime Continent and the western Pacific as revealed by satellite. Mon. Wea. Rev., 134, 1581-1599.

Liu, C., E. J. Zipser, and S. W. Nesbitt, 2007: Global distribution of tropical deep convection: Different perspectives from TRMM infrared and radar data. J. Climate, 20, 489-503.

Machado, L. A. T., and W. Rossow, 1993: Structural characteristics and radiative properties of tropical cloud clusters. Mon. Wea. Rev., 121, 3234-3260.

_ and H. Laurent, 2004: The convective system area expansion over Amazonia and its relationships with convective system life duration and high-level wind divergence. Mon. Wea. Rev., 132, 714-725.

—, M. Desbois, and J.-Ph. Duvel, 1992: Structural characteristics of deep convective systems over tropical Africa and the Atlantic Ocean. Mon. Wea. Rev., 120, 392-406.

—, W. B. Rossow, R. L. Guedes, and A. W. Walker, 1998: Life cycle variations of mesoscale vonvective systems over the Americas. Mon. Wea. Rev., 126, 1630-1654.

Mapes, B. E., and R. A. Houze Jr., 1993: Cloud clusters and superclusters over the oceanic warm pool. J. Atmos. Sci., 50, 2026-2037.

— T. T. Warner, and M. Xu, 2003: Diurnal patterns of rainfall in northwestern South America. Part III: Diurnal gravity waves and nocturnal convection offshore. Mon. Wea. Rev., 131, 830-844.

Mather, J. H., T. P. Ackerman, W. E. Clements, F. J. Barnes, M. D. Ivey, L. D. Hatfield, and R. M. Reynolds, 1998: An atmospheric radiation and cloud station in the tropical western Pacific. Bull. Amer. Meteor. Soc., 79, 627-642.

May, P. T., A. R. Jameson, T. D. Keenan, P. E. Johnston, and C. Lucas, 2002: Combined wind profiler/polarimetric radar studies of the vertical motion and microphysical characteristics of tropical sea-breeze thunderstorms. Mon. Wea. Rev., 130, 2228-2239.

_ J. H. Mather, G. Vaughan, and C. Jakob, 2008: Characterizing oceanic convective cloud systems: The Tropical Warm Pool International Cloud Experiment. Bull. Amer. Meteor. Soc., 89, 153-155.

McBride, J. L., and W. M. Frank, 1999: Relationships between stability and monsoon convection. J. Atmos. Sci., 56, 24-36.

Merchant, C. J., J. J. Simpson, and A. R. Harris, 2003: A crosscalibration of GMS-5 thermal channels against ATSR-2. Remote Sens. Environ., 84, 268-282.

Schumacher, C., and R. A. Houze, 2003: Stratiform rain in the tropics as seen by the TRMM Precipitation Radar. J. Climate, 16, 1739-1756.

Tokuno, M., and S. Kurihara, 1999: Intercalibration of GMS-5 IR channels and NOAA-14 AVHRR channels 4 and 5. Adv. Space Res., 23, 1349-1356. 
Wheeler, M. C., and H. H. Hendon, 2004: An all-season real-time multivariate MJO index: Development of an index for monitoring and prediction. Mon. Wea. Rev., 132, 1917-1932.

Williams, M., and R. A. Houze Jr., 1987: Satellite-observed characteristics of winter monsoon cloud clusters. Mon. Wea. Rev. 115, 505-519.

Yang, G.-Y., and J. Slingo, 2001: The diurnal cycle in the tropics. Mon. Wea. Rev., 129, 784-801.
Yuter, S. E., and R. A. Houze, 1998: The natural variability of precipitating clouds over the western Pacific warm pool. Quart. J. Roy. Meteor. Soc., 124, 53-99.

Zipser, E. J., D. J. Cecil, C. Liu, S. W. Nesbitt, and D. P. Yorty, 2006: Where are the most intense thunderstorms on Earth? Bull. Amer. Meteor. Soc., 87, 1057-1071.

Zuidema, P., 2003: Convective clouds over the Bay of Bengal. Mon. Wea. Rev., 131, 780-798. 